\title{
The relationship between mantle potential temperature and oceanic lithosphere buoyancy
}

\author{
O.M. Weller*1, A. Copley ${ }^{1}$, W.G.R. Miller ${ }^{1}$, R.M. Palin ${ }^{2}$, B. Dyck ${ }^{3}$
}

1 - Department of Earth Sciences, University of Cambridge, Downing Street, Cambridge, CB2 3EQ, UK.

2 - Department of Geology and Geological Engineering, Colorado School of Mines, Golden, 80401 Colorado, USA.

3 - Department of Earth Sciences, Simon Fraser University, University Drive, Burnaby, V5A 1S6, Canada.

*corresponding author: ow212@cam.ac.uk

\section{Abstract}

The Earth's mantle potential temperature $\left(T_{\mathrm{P}}\right)$ is thought to have cooled by $\sim 250{ }^{\circ} \mathrm{C}$ since the Archean, causing a progressive change in both the structure and composition of oceanic lithosphere. These variables affect the negative buoyancy of subducting slabs, which is known to be an important force in driving plate motions. However, the relationship between $T_{\mathrm{P}}$ and slab buoyancy remains unclear. Here, we model the formation and subduction of oceanic lithosphere as a function of $T_{\mathrm{P}}$, to investigate how $T_{\mathrm{P}}$ influences the buoyancy of subducting slabs, and by extension how buoyancy forces may have changed through time. First, we simulate isentropic melting of peridotite at mid-ocean ridges over a range of $T_{\mathrm{P}}\left(1300-1550{ }^{\circ} \mathrm{C}\right)$ to calculate oceanic lithosphere structure and composition. Second, we model the thermal evolution of oceanic plates undergoing subduction for a variety of scenarios (by varying lithospheric thickness, slab length and subduction velocity). Finally, we integrate the structural, compositional and thermal constraints to forward model subduction metamorphism of oceanic plates to determine down-going slab density structures. When compared with ambient mantle, these models allow us to calculate buoyancy forces acting on subducting slabs. Our results indicate that oceanic lithosphere derived from hotter mantle has a greater negative buoyancy, and therefore subduction potential, than lithosphere derived from cooler mantle for a wide range of 
subduction scenarios. With respect to the early Earth, this conclusion supports the viability of subduction, and models of subduction zone initiation that invoke the concept of oceanic lithosphere being primed to subduct. However, we also show that decreases to lithosphere thickness and slab length, and reduced crustal hydration, progressively reduce slab negative buoyancy. These results highlight the need for robust estimates of early Earth lithospheric properties when considering whether subduction was operative at this time. Nevertheless, our findings suggest that subduction processes on the early Earth may have been uniformitarian.

Keywords: Mantle potential temperature; buoyancy force; subduction metamorphism; plate tectonics; phase equilibria modelling; secular change.

\section{Introduction}

The hallmark of modern-day plate tectonics is the horizontal motion of rigid plates across the surface of the Earth (McKenzie \& Parker, 1967), with new oceanic lithosphere created at mid-ocean ridges (MORs) and destroyed in subduction zones. It remains debated as to when this style of plate tectonics began (Stern, 2005; Turner et al., 2014; Weller \& StOnge, 2017), but there is consensus that the characteristics of plate structure and motion are likely to have evolved due to cooling of the Earth's mantle potential temperature $\left(T_{\mathrm{P}}\right)$. Although the exact values remain contentious (e.g. Aulbach \& Arndt, 2019), $T_{\mathrm{P}}$ is thought to have decreased from a maximum of $\sim 1500-1600{ }^{\circ} \mathrm{C}$ at $c a .3$ Ga to $\sim 1300-1350{ }^{\circ} \mathrm{C}$ at the present day (Herzberg et al., 2010; Hawkesworth et al., 2016; Tappe et al., 2018).

Temporal changes in $T_{\mathrm{P}}$ will have affected MOR melting and subduction pressuretemperature $(P-T)$ conditions, with consequences for the negative buoyancy of subducting oceanic slabs, which is thought to be an important force in driving plate motions (Forsyth \& Uyeda, 1975). Cooling of the mantle would lead to interception of the peridotite solidus at shallower depths, reducing the thickness and changing the composition of oceanic crust and residual mantle produced during adiabatic decompression (White et al., 1992; Langmuir et al., 1992). These structural and compositional changes would subsequently affect the metamorphic evolution, hence density profile, of slabs during subduction (Sleep \& Windley, 1982; Palin \& White, 2016). Therefore, is it important to quantify how slab buoyancy has co-evolved with $T_{\mathrm{P}}$, as buoyancy changes through time can be expected to have played an important role in the tectonic evolution of the Earth.

Multiple lines of evidence have been used to suggest that subduction was operating on some scale in the Archean, including subduction-zone geochemical signatures in Archean mafic rocks (Turner et al., 2014), evolving Archean diamond inclusion suites (Shirey \& Richardson, 2011) and geochemistry (Smart et al., 2016), zircon oxygen isotope records (Dhuime 
et al., 2012), and Archean tonalite-trondjhemite-granodiorite trace element systematics (Rapp et al., 2003). However, the absence of Archean high-pressure and low-temperature metamorphic rocks has been used to argue against widespread subduction (Brown, 2014), although it is unclear to what extent this signal is influenced by preservation bias. In light of this controversy, an aim of this paper is to assess the viability of subduction in the Archean.

The relationship between oceanic plate composition, buoyancy and hotter $T_{\mathrm{P}}$ in the Archean has long been the subject of analysis to explore whether subduction could have been operative (e.g. Bickle, 1978; Sleep \& Windley, 1982; Arndt, 1983; Vlaar et al., 1994; Foley et al., 2003; Hynes, 2014). However, conclusions vary markedly between studies, largely due to differences in their choice of model parameters (e.g. thickness and composition of oceanic crust), reflective of the paucity of unambiguous observational constraints for the early Earth (Hadean-Archean; Korenaga, 2006). Unlike previous studies that impose crustal thicknesses and chemistry, in this paper we present a petrologically self-consistent model for both the formation and subduction of oceanic crust and the underlying lithospheric mantle. This model uses recently formulated activity-composition $(a-X)$ relations parametrised for mafic (Green et al., 2016) and ultramafic (Jennings \& Holland, 2015) systems, which make it possible to examine evolving phase equilibria in both the crustal and mantle portions of the oceanic lithosphere using a forward modelling approach. We apply the new $a-X$ relations to replicate MOR melting at variable $T_{\mathrm{P}}$, by determining isentropic decompression paths and applying melt fractionation, to calculate the major element composition and thickness of melts and residue. These values are propagated through all subsequent calculations, which simulate subduction metamorphism, to determine the buoyancy of subducting oceanic lithosphere as a function of $T_{\mathrm{P}}$. Our results provide quantitative constraints on the geodynamic evolution of the Earth, and highlight the importance of lithospheric thickness, hydration state and slab length, as well as $T_{\mathrm{P}}$, in determining subduction potential.

\section{Petrological modelling of mantle melting}

To create a petrologically self-consistent model of the production and subduction of oceanic lithosphere, we first simulate decompression melting of asthenospheric mantle using phase equilibria modelling of the KLB-1 bulk composition over $P-T$ conditions of $0-60 \mathrm{GPa}$ and $800-2000{ }^{\circ} \mathrm{C}$ (Fig. 1a-c). KLB-1 is the most widely used natural analogue of the fertile upper mantle (Davis et al., 2009), and has a comparable major element bulk composition to estimates of the primitive upper mantle (McDonough \& Sun, 1995). Phase equilibria diagrams (pseudosections) are constructed using THERMOCALC v3.40 (Powell et al., 1998) and the internally consistent thermodynamic dataset ds-62 of Holland \& Powell (2011). Mod- 
elling is performed in the $\mathrm{Na}_{2} \mathrm{O}-\mathrm{CaO}-\mathrm{FeO}-\mathrm{MgO}-\mathrm{Al}_{2} \mathrm{O}_{3}-\mathrm{SiO}_{2}-\mathrm{O}_{2}-\mathrm{Cr}_{2} \mathrm{O}_{3}$ (NCFMASOCr) compositional system using the $a-X$ relations of Jennings \& Holland (2015), comprising: garnet, clinopyroxene, orthopyroxene, olivine, spinel-chromite, plagioclase, and silicate melt.

\subsection{Simulating adiabatic decompression and melt fractionation}

To simulate MOR mantle melting, it is necessary to calculate isentropic $P-T$ paths to replicate adiabatic decompression (McKenzie \& Bickle, 1988), and to fractionate the bulk composition, as multiple lines of evidence indicate that melt fractionation is an important process at MORs (Langmuir et al., 1977; Johnson et al., 1990; Niu, 1997; Zhu et al., 2011; Behn \& Grove, 2015). We model these behaviours by solving for lines of constant entropy in THERMOCALC, and then removing melt at 0.05 mode $(\sim 5$ vol. \%) intervals along these paths, with all melt removed from the system at each step (Supplementary Information Section $1.1 \& 1.2$ ). We explore three $T_{\mathrm{P}}$ of $1300{ }^{\circ} \mathrm{C}, 1425{ }^{\circ} \mathrm{C}$ and $1550{ }^{\circ} \mathrm{C}$ (dashed blue lines, Fig. 1a-c), as this temperature range spans suggested mantle potential temperatures through time (Herzberg et al., 2010).

The imposed $5 \%$ melt fraction $(\mathrm{F})$ extraction threshold is greater than is reported for MOR melting, where $\mathrm{F}$ is thought to range from $~ 0.1$ to $3 \%$ depending on volatile content and viscosity of the melt (Johnson et al., 1990; Faul, 2001). Furthermore, it is likely that some melt is retained in the source region (Faul, 2001), and the final pressure of melting may be non-zero (Korenaga, 2006), indicating that more sophisticated modelling is required to reproduce MOR processes in detail (e.g. Behn \& Grove, 2015). However, the requirement of this study is only to capture the major element systematics of MOR melting. As shown below, our step-wise fractionation approach reproduces the major element chemistry and thickness of modern oceanic crust, indicating that our modelling successfully captures the macroscopic behaviour of mantle melting.

\subsection{Modelled oceanic lithosphere composition and structure}

Figure $1 \mathrm{a}-\mathrm{c}$ shows the results of isentropic melting with fractional removal of melt for the three $T_{\mathrm{P}}$, with each horizontal strip corresponding to a unique bulk composition that represents the residue after removal of 0.05 mode melt from the previous depth interval (Tables S1-S6). The solidus (bold red lines, Fig. 1a-c) is intercepted in the spinellherzolite field for $T_{\mathrm{P}}=1300{ }^{\circ} \mathrm{C}$ (Fig. 1a), and the garnet-lherzolite field for $T_{\mathrm{P}}=1425{ }^{\circ} \mathrm{C}$ and $1550{ }^{\circ} \mathrm{C}$ (Fig. 1b,c). Melt removal reduces the fertility of the system, which elevates the solidus temperature, resulting in the modelled sawtooth profile of the solidus. Figure $\mathrm{S} 1$ shows the unfractionated (batch) scenario for comparison. Figure $1 \mathrm{~d}-\mathrm{f}$ shows the 
proportion and composition of fertile mantle (green), residual mantle (greys) and melt (reds) as a function of pressure along each isentrope. At all pressures, the cumulative bulk composition is equal to KLB-1, such that mass is preserved (Supplementary Information $1.3)$

Integrating the melt area with an assumed density of $3000 \mathrm{~kg} \mathrm{~m}^{-3}$ generates calculated crustal thicknesses of $7.5 \mathrm{~km}, 13.8 \mathrm{~km}$ and $24.3 \mathrm{~km}$ for $T_{\mathrm{P}}$ of $1300{ }^{\circ} \mathrm{C}, 1425{ }^{\circ} \mathrm{C}$ and 1550 ${ }^{\circ} \mathrm{C}$, respectively. The thickness of melt extracted from the $1300{ }^{\circ} \mathrm{C} T_{\mathrm{P}}$ isentrope $(7.5 \mathrm{~km})$ closely matches observations of present-day average oceanic crust (White et al., 1992), and the values for higher $T_{\mathrm{P}}$ are concordant with observations of thicker oceanic crust at plume-ridge settings, such as Iceland (Darbyshire et al., 2000).

For all $T_{\mathrm{P}}$, the fractionated melt compositions evolve with decreasing depth to higher $\mathrm{Si}$ and $\mathrm{Mg}$, and lower $\mathrm{Ca}, \mathrm{Al}$ and $\mathrm{Na}$ concentrations (circles, Fig. 2). The depth-integrated 'average' melt composition (Table 1) is picritic in all cases (Le Bas, 2000), with MgO contents of $12.1 \mathrm{wt} \%, 14.3 \mathrm{wt} \%$ and $17.4 \mathrm{wt} \%$ for the $1300{ }^{\circ} \mathrm{C}, 1425{ }^{\circ} \mathrm{C}$ and $1550{ }^{\circ} \mathrm{C}$ isentropes, respectively (diamonds, Fig. 2). These compositions are in good agreement with estimates for primary oceanic crust through time (Herzberg et al., 2007; White \& Klein, 2014). Our melting model also determines the thickness and composition of residual mantle from which melt has been extracted (grey areas, Fig. 1d-f). With an assumed density of $3300 \mathrm{~kg} \mathrm{~m}^{-3}$, residual mantle thickness increases from 48.5 to $96.6 \mathrm{~km}$ over the considered $T_{\mathrm{P}}$ range, and becomes progressively depleted in $\mathrm{Si}, \mathrm{Al}, \mathrm{Ca}, \mathrm{Na}$ and enriched in $\mathrm{Mg}$ (Table 1).

Using the results of our melting models, we constructed synthetic depth sections of oceanic lithosphere derived from decompression melting at $T_{\mathrm{P}}$ of $1300{ }^{\circ} \mathrm{C}, 1425{ }^{\circ} \mathrm{C}$ and $1550{ }^{\circ} \mathrm{C}$ (Supplementary Information Section 1.3). The models have three compositional layers: a crustal layer, a residual mantle layer from which the melts that form the crust have been extracted, and a fertile mantle (KLB-1) layer. Our calculated depth-integrated bulk compositions and layer thicknesses are used for all subsequent calculations (Table 1), which focus first on the thermal profile of subduction, and then on density, to determine slab buoyancy.

\section{Thermal modelling of subducting slabs}

We calculated temperature distributions for subducting slabs dipping at $45^{\circ}$, with lengths varying from $50-300 \mathrm{~km}$, thicknesses ranging from $40-90 \mathrm{~km}$, subduction velocities of 5-20 $\mathrm{mm} \mathrm{yr}^{-1}$, and subducting into an ambient mantle with potential temperatures of $1300{ }^{\circ} \mathrm{C}$, $1425^{\circ} \mathrm{C}$ and $1550{ }^{\circ} \mathrm{C}$ (e.g. Fig. 3). The range of parameters are chosen to be representative of plausible subduction geometries (Syracuse et al., 2010), and will influence the absolute 
values of the buoyancy forces we subsequently calculate. However, our main focus will be on comparing the relative buoyancy changes produced by varying these parameters.

\subsection{Numerical approach}

Previous studies have obtained analytical expressions for the temperature distribution in subducting oceanic lithosphere (McKenzie, 1969; Toksöz et al., 1971; Davies, 1999; England \& Wilkins, 2004). We build upon this work, but take a numerical approach, to allow us to calculate the thermal structure resulting from advection down the dip of the slab, and diffusion both parallel and perpendicular to the slab upper and lower surfaces, which is necessary when considering short slabs whose length is similar to their thickness. We also take a numerical approach because McKenzie et al. (2005) demonstrated that the temperature dependence of thermal parameters can play an important role in controlling the thermal structure. By taking a numerical approach we are able to include this effect, using the expressions for this temperature dependence given in McKenzie et al. (2005).

We model the down-dip advection of heat due to slab motion, and also diffusion parallel and perpendicular to the slab boundaries. We assume that the slab remains rigid as it subducts. For the initial input geotherm at the up-dip end of the slab, we use a thermal steady-state geotherm calculated for oceanic lithosphere at the surface of the Earth (McKenzie et al., 2005), incorporating the lithosphere thickness and $T_{\mathrm{P}}$ used in each model. As the slab subducts, we impose the mantle isentropic temperature on the lower and down-dip margins of the slab, calculated for the $T_{\mathrm{P}}$ used in each model. The isentropic temperature is used on the down-dip nose of the slab to simulate the conditions during the onset of subduction. For the upper boundary of the slab, we use the steadystate lithosphere temperature at depths where the slab is in contact with the lithosphere, and the isentropic temperature beneath this depth. These boundary conditions result in the slab heating up as it subducts. Operator-splitting is used to treat the advective and diffusive terms in the advection-diffusion equation separately (Press et al., 1992). The diffusion term is solved using a joint implicit-explicit (Crank-Nicolson) finite-difference scheme, and the advection term by upwind differencing (Press et al., 1992).

A similar approach to calculating temperature distributions in subducting oceanic lithosphere was previously used by Emmerson \& McKenzie (2007). Our approach differs from their study by calculating diffusion both parallel and perpendicular to the slab upper and lower surfaces, whereas Emmerson \& McKenzie (2007) only considered one direction because they were studying longer slabs where that assumption holds true. Emmerson \& McKenzie (2007) also modelled and discussed the thermal behaviour of the surrounding mantle, as it is not known whether subducting slabs are flanked by regions of cooled ambient mantle, or whether convection surrounding the slab is vigorous enough to remove such 
regions and keep the slab boundaries at the isentropic temperature, or thermally erode the slab itself. Due to this uncertainty, we take the simple approach of keeping the slab boundaries at the isentropic temperature, but note that this approach could result in a slight over-estimate of slab internal temperatures if the slab is actually flanked by cooled ambient mantle (by $\sim 100{ }^{\circ} \mathrm{C}$ at the centre of the slab; Emmerson \& McKenzie, 2007). The effect will be similar in all our models, so is not significant given that our purpose here is to compare relative values between the different models.

\subsection{Thermal structure of subducting lithospheric slabs}

Example thermal structures are shown in Fig. 3 for slabs with the present-day oceanic lithosphere thickness (90 km; Crosby et al., 2006), which are $300 \mathrm{~km}$ long, dipping at $45^{\circ}$, and subducting at $10 \mathrm{~mm} \mathrm{yr}^{-1}$ into mantle with potential temperatures of $1300{ }^{\circ} \mathrm{C}$, $1425{ }^{\circ} \mathrm{C}$ and $1550{ }^{\circ} \mathrm{C}$. The dashed grey lines on Fig. 3 show the boundaries between compositional layers of the oceanic lithosphere in each scenario, calculated from our melting models (Table 1). The inset on Fig. 3c depicts the reference frame used for the plotting. The thermal modelling thus allows us to estimate the $P-T$ range that each slab component would encounter during subduction metamorphism, for a given set of subduction parameters.

\section{Density calculations}

Densities for each petrologically distinct layer of the oceanic lithosphere (Table 1), calculated using Theriak-Domino (De Capitani \& Petrakakis, 2010; Supplementary Information Section 2), are presented in Fig. 4 over $P-T$ ranges relevant to our thermal modelling scenarios. The results shown in Fig. 4 are used to determine slab density structures in subsequent buoyancy calculations. Pseudosections showing the associated mineral assemblages (from which the densities are calculated) are presented in Figs. S2-S6.

We have calculated one set of densities for fertile and residual mantle compositions (Fig. 4d-f,j), whereas two are provided for the crustal components (Fig. 4a-c,g-i). The two sets of crustal densities cover the end-member scenarios of completely anhydrous (Fig. 4ac) or fluid-saturated (Fig. 4g-i), and are discussed below. Calculations for the anhydrous crust (Fig. 4a-c), residual mantle (Fig. 4d-f) and fertile mantle (Fig. 4j) used the same model parameters as described above for MOR melting, including the NCFMASOCr compositional system, thermodynamic dataset ds-62 (Holland \& Powell, 2011), and the $a-X$ relations of Jennings \& Holland (2015). Calculations for the hydrous crust (Fig. 4g-i) were performed in the $\mathrm{Na}_{2} \mathrm{O}-\mathrm{CaO}-\mathrm{FeO}-\mathrm{MgO}-\mathrm{Al}_{2} \mathrm{O}_{3}-\mathrm{SiO}_{2}-\mathrm{H}_{2} \mathrm{O}-\mathrm{O}_{2}$ (NCFMASHO) compositional system, using the same database as above and the $a-X$ relations of Green et al. 
(2016).

\subsection{Hydration state of the crust}

There are numerous possibilities for the content and distribution of water in oceanic crust, because initially dry MOR basalts can be variably hydrated by a number of processes prior to subduction (e.g. Langmuir et al., 1977; White \& Klein, 2014). We account for this spectrum of hydration states in our buoyancy calculations (Section 6), by using the two sets of crustal densities (completely anhydrous, Fig. 4a-c, or water-saturated, Fig. 4g-i) as representative end-members. For the purposes of this study, the consideration of crustal hydration state is important because water-bearing equilibrium assemblages have lower densities than the equivalent anhydrous equilibrium assemblage (Fig. 4).

At low $P-T$, hydrous bulk compositions can be expected to maintain equilibrium behaviour, as water assists in catalysing reactions (Guiraud et al., 2001), such that Fig. 4g-i densities can be applied in subsequent buoyancy calculations. However, we cannot make the same assumption for anhydrous bulk compositions (i.e. applying the sampled low $P-T$ densities of Fig. 4a-c), as such crust would likely behave metastably and persist as a low density basalt until the temperature was sufficiently high to catalyse reactions. Therefore, for scenarios below that invoke anhydrous crust, we impose the density of basalt until the temperature is high enough to overcome kinetic barriers.

At high $P-T$, densities of hydrous and anhydrous crustal bulk compositions converge, as initially hydrous bulk compositions progressively dehydrate to anhydrous assemblages due to sub-solidus devolatilisation reactions (see plots of $\mathrm{H}_{2} \mathrm{O}$ content of the solid assemblage, Figs. S4-6). Convergence is reached in the eclogite facies, where solid assemblages are composed of minerals with no structurally-bound $\mathrm{H}_{2} \mathrm{O}$. Therefore, for subsequent buoyancy calculations that invoke hydrous crust, we only need to consider the hydrous crustal densities for the sampled $P-T$ range prior to dehydration. Thereafter, we use densities of the anhydrous crust (Fig. 4a-c). This transition occurs at the highest pressure for the $T_{\mathrm{P}}$ $=1550{ }^{\circ} \mathrm{C}$ crust composition, hence the largest $P-T$ area is shown in Fig. 4i. We switch from the hydrous to the anhydrous system for the initially hydrous crust to simulate open system loss of water, so that we are able to calculate the position of the dry solidus at high temperatures (Fig. S2). Wet melting is not considered in our calculations, as nearly all modelled hydrous crust reaches the point of dehydration prior to the wet solidus within the considered subduction $P-T$ ranges (Fig. S4-6). 


\subsection{Density results}

Calculated densities indicate that for all mantle compositions (Fig. 4d-f,j), density mostly varies between $\sim 3300-3500 \mathrm{~kg} \mathrm{~m}^{-3}$ for $P-T$ conditions of relevance to subduction. For a given $P-T$, the variation between residual mantle densities calculated for different $T_{\mathrm{P}}$ is minimal $\left(\Delta \rho \leq 10 \mathrm{~kg} \mathrm{~m}^{-3}\right)$. However, as expected, density systematically increases as $T_{\mathrm{P}}$ decreases, as the mantle has been less depleted by melting. Similarly, KLB-1 mantle yields a higher density than residual mantle compositions for a given $P-T(\Delta \rho \sim 22-33$ $\mathrm{kg} \mathrm{m}^{-3}$ ), owing to its more fertile (lherzolitic) composition and thus higher garnet mode (Fig. S3).

Conversely, crustal compositions show a much more extreme range in density, increasing from $\sim 3000$ to $3600 \mathrm{~kg} \mathrm{~m}^{-3}$ over the $P-T$ regions of interest. The density increase mostly occurs at $T<800{ }^{\circ} \mathrm{C}$, closely associated with increasing garnet abundance during transitions into the eclogite facies (Fig. 4g-i; Figs. S4-S6). At higher temperatures, minimal density variation is observed, as the eclogite facies is characterised by large assemblage fields with little change in modal proportions or compositions (Fig. 4a-c; Fig. S2). In detail, crustal densities associated with higher $T_{\mathrm{P}}$ compositions typically yield lower densities for a given $P-T$, as more magnesian bulk compositions decrease garnet mode and increase the stability of low-density greenschist-facies indicator minerals such as chlorite (Fig. S6; cf. Palin \& White, 2016).

\section{Buoyancy force calculations}

Thermal model $P-T$ arrays for a given subduction scenario (e.g. Fig. 3a) were used to extract the corresponding densities of each slab component from Fig. 4 to determine downgoing slab density distributions (e.g. Fig. 5a). Slab buoyancy forces were then quantified by calculating the difference between the density of the slab and the ambient mantle, integrated over the entire slab, and multiplied by the acceleration due to gravity. Unless otherwise stated, scenarios assume that the incoming crust was fully hydrous, and use the hydrated crust density values (Fig. $4 \mathrm{~g}-\mathrm{i}$ ).

Figure 5a provides an example of a calculated density structure of $90-\mathrm{km}$ thick oceanic lithosphere undergoing subduction into mantle with $T_{\mathrm{P}}=1300^{\circ} \mathrm{C}$. The lithospheric mantle density is fairly uniform, due to the large $P-T$ assemblage fields in ultramafic systems meaning there are few density jumps associated with assemblage changes (e.g. Fig. 1a). In contrast, the crustal density increases rapidly between down-dip distances of 30-60 km, due to the reactions associated with conversion from low-density basalt to high-density eclogite. 
Figure 5b shows the density structure of the ambient mantle, formed of the oceanic lithosphere underlain by mantle at the isentropic temperature gradient, calculated for the area that the subducting slab is replacing. The slab has been modelled as $90-\mathrm{km}$ thick lithosphere subducting at $45^{\circ}$, but is shown with coordinates aligned to the length of the slab. As such, features with angles of $45^{\circ}$ on Fig. 5 are horizontal relative to the Earth's surface, with the density band between $(0,90)$ and $(90,0)$ representing the base of the lithosphere (inset, Fig. 3).

Figure 5c shows the density difference of the slab minus the ambient, with red regions negatively buoyant (i.e. the slab is more dense) and blue regions positively buoyant (i.e. the ambient is more dense). The crustal basalt to eclogite transition is particularly evident on this plot, with a marked density increase of $\sim 400 \mathrm{~kg} \mathrm{~m}^{-3}$ at a down-dip distance of $50 \pm 10 \mathrm{~km}$, shifting the crust from being the most positively buoyant component of the modelled slab to the most negatively buoyant. The subducting lithospheric mantle is mostly slightly negatively buoyant, owing to the lower temperature of the slab relative to the ambient mantle. The combined effect of the three subducting layers gives a slab negative buoyancy force of $13.6 \times 10^{12} \mathrm{~N}$ (per unit distance into the page). The crust makes a $19 \%$ contribution to this total despite representing just $8 \%$ of the area; the residual mantle contributes $53 \%$ with $54 \%$ of the area; and the KLB-1 mantle makes a $28 \%$ contribution with $38 \%$ of the area. While this analysis highlights the importance of eclogitic crust for slab buoyancy, it also shows that the slab lithospheric mantle density should be modelled carefully, as for this scenario it constitutes $\sim 80 \%$ of the buoyancy force. This calculation also indicates that more detailed modelling of crustal architecture (e.g. accounting for lower crustal cumulate compositions) would not affect the first-order results of this study, as the buoyancy signal is dominated by mantle contributions arising from the cool slab interior.

Equivalent analyses for $T_{\mathrm{P}}=1425{ }^{\circ} \mathrm{C}$ (Fig. 6) and $T_{\mathrm{P}}=1550{ }^{\circ} \mathrm{C}$ (Fig. 7) show similar trends as the $T_{\mathrm{P}}=1300{ }^{\circ} \mathrm{C}$ scenario, with the signal dominated by the mantle contribution despite the most marked density contrast occurring in the crust. Crucially, the results indicate that slab negative buoyancy force increases as $T_{\mathrm{P}}$ increases: $14.9 \times 10^{12} \mathrm{~N}$ (per unit distance into the page) for $T_{\mathrm{P}}=1425^{\circ} \mathrm{C}$, and $19.5 \times 10^{12} \mathrm{Nm}^{-1}$ for $T_{\mathrm{P}}=1550$ ${ }^{\circ} \mathrm{C}$.

Figure 8 explores the effect of imposing a metastable lower crust for $T_{\mathrm{P}}=1550{ }^{\circ} \mathrm{C}$, by inserting a layer of constant density $\left(3000 \mathrm{~kg} \mathrm{~m}^{-3}\right)$ into the base of the model crust. This scenario simulates the effect of a thickened oceanic crust only being fluid saturated in the upper $10 \mathrm{~km}$, with the lower crust fully anhydrous and unreactive (until a threshold temperature of $800{ }^{\circ} \mathrm{C}$ ), reflecting the concept that only the upper part of thickened oceanic crust may be hydrated (e.g. Foley et al., 2003). The addition of a buoyant lower crust reduces the net slab negative buoyancy force to $14.7 \times 10^{12} \mathrm{~N} \mathrm{~m}^{-1}$; a reduction of 
$\sim 25 \%$ compared with the equivalent scenario without the metastable layer (Fig. 7).

\section{Results}

Figure 9 shows negative buoyancy force as a function of $T_{\mathrm{P}}$ and a variety of thermal model parameters (lithospheric thickness, slab length and subduction velocity), which we examine in turn. The parameters were chosen to cover some of the main sources of uncertainty in geodynamic modelling of plate motions and subduction with hotter $T_{\mathrm{P}}$ (Korenaga, 2006).

\subsection{Lithospheric thickness}

Figure 9a explores the effect of varying oceanic lithosphere thickness (from 40 to $90 \mathrm{~km}$ ) on slab negative buoyancy (for 300-km long slabs subducting at $10 \mathrm{~mm} \mathrm{yr}^{-1}$ ). Focussing first on the calculations for a lithosphere thickness of $90 \mathrm{~km}$, the blue circle shows the result for the $T_{\mathrm{P}}=1300{ }^{\circ} \mathrm{C}$ scenario (labelled 'a' on Fig. 9, calculated from the scenario shown in Fig. 5), which is representative of modern oceanic lithosphere (Crosby et al., 2006) and used as a reference value hereafter. The open red circle labelled 'b' shows a calculation for a hypothetical situation in which oceanic lithosphere with the modern-day structure and composition is subducting into mantle with $T_{\mathrm{P}}=1550{ }^{\circ} \mathrm{C}$. This calculation isolates the effect of only changing $T_{\mathrm{P}}$ during subduction. The slab negative buoyancy force is greater than the present-day value because the density difference between the ambient mantle and downgoing slab is greater at higher $T_{\mathrm{P}}$, despite the absolute density of both being less at higher temperatures (Fig. 4), as the temperature differential between the slab and the ambient mantle is greater at higher $T_{\mathrm{P}}$.

The filled red circle labelled 'c' on Fig. 9a also represents a 90-km thick slab subducting into mantle with $T_{\mathrm{P}}=1550{ }^{\circ} \mathrm{C}$, but shows the effects of incorporating the crust/residue compositions and thicknesses that result from decompression melting at $T_{\mathrm{P}}=1550{ }^{\circ} \mathrm{C}$ (as depicted in Fig. 7). The slab negative buoyancy force for this scenario is less than shown by the open red circle (which considers only thermal effects during subduction), because the metamorphic assemblages in the $T_{\mathrm{P}}=1550{ }^{\circ} \mathrm{C}$ derived slab are less dense than those calculated from the present-day structure and composition (Fig. 4). However, the increase in compositional buoyancy is insufficient to counteract the thermal buoyancy effects, so these slabs are more negatively buoyant than the present-day case. The value for $T_{\mathrm{P}}=$ $1425^{\circ} \mathrm{C}$ (grey circle labelled 'd' on Fig. 9a, calculated from the scenario shown in Fig. 6), as expected, falls between those for $1300{ }^{\circ} \mathrm{C}$ and $1550{ }^{\circ} \mathrm{C}$.

The conclusion that thermal effects outweigh those due to composition is also true if we 
incorporate metastable basalt layers in the lower crust, e.g. resulting from incomplete crustal hydration before subduction (pink circle labelled 'e' on Fig. 9a, calculated from the scenario shown in Fig. 8). Nevertheless, the large decrease in negative buoyancy force for the metastable scenario indicates that hydration state, which is poorly constrained on the early Earth, is an important parameter choice when modelling slab buoyancy.

While some previous studies have assumed that the ancient oceanic lithospheric mantle would have had a similar thickness to today (Klein et al., 2017), some models indicate that the higher Rayleigh number resulting from a hotter $T_{\mathrm{P}}$ may yield a thinner oceanic lithosphere (Solomatov, 1995). This effect primarily arises from the temperature dependence of viscosity allowing the lower lithosphere to be removed by Rayleigh-Taylor instabilities more effectively. However, Korenaga (2006) suggested that this effect may be counterbalanced by the deeper interception of the solidus for hotter $T_{\mathrm{P}}$ (e.g. Fig. 1) causing 'dehydration stiffening', suppressing convective instabilities and enhancing growth of the thermal boundary layer. The remaining results on Fig. 9a indicate that lithospheric thickness is a critical parameter choice, because a thickness reduction of $\sim 10 \mathrm{~km}$ for $T_{\mathrm{P}}=$ $1425{ }^{\circ} \mathrm{C}$ and $\sim 50 \mathrm{~km}$ for $T_{\mathrm{P}}=1550{ }^{\circ} \mathrm{C}$ would be sufficient to overwhelm the other thermal and compositional effects described above, and make all model scenarios on Fig. 9a more positively buoyant than the present-day value.

An additional complexity is that buoyancy forces for the $T_{\mathrm{P}}=1550{ }^{\circ} \mathrm{C}$ scenarios and for thin lithospheres may be lower bounds, as in these scenarios the solidus is intercepted at asthenospheric depths, leading to melt being generated in the convecting mantle. It is beyond the scope of this study to incorporate this effect, but conceptually if this melt ascended into the lithosphere, over-thickened oceanic crust could be generated. While there are trade-offs with thick crust potentially behaving metastably (e.g. Fig. 8), increased crustal thickness would likely increase the negative buoyancy of a subducting slab by yielding a greater volume of eclogite.

\subsection{Slab length}

Another source of debate for the early Earth is the length-scales over which the slabs remain coherent, with some authors suggesting that Archean oceanic slabs would not have had sufficient strength to remain coherent (van Hunen \& Moyen, 2012). However, other authors contend that while slabs do become weaker at higher temperature, their relative strength would be greater due to larger viscosity contrasts with the surrounding hotter mantle, and increased thickness of residual mantle stiffened by melt depletion, such that it is sensible to invoke slab coherency (Korenaga, 2006; Klein et al., 2017). Figure 9b explores the effect of changing slab length (for $T_{\mathrm{P}}=1300{ }^{\circ} \mathrm{C}$ and $T_{\mathrm{P}}=1550{ }^{\circ} \mathrm{C}$ ), and indicates that this parameter choice is also extremely influential for slab buoyancy. For 
example, a reduction in slab length of $\sim 75 \mathrm{~km}$ would be sufficient to decrease the $T_{\mathrm{P}}=$ $1550{ }^{\circ} \mathrm{C}$ buoyancy force below the present-day value. However, for a given slab length, the relative buoyancy is still governed by $T_{\mathrm{P}}$, with hotter $T_{\mathrm{P}}$ yielding a greater negative buoyancy force.

\subsection{Subduction velocity}

Figure 9c shows the effect of subduction velocity on buoyancy force. Again, this parameter is widely disputed in the Archean, with some authors arguing for more rapid plate spreading rates than the present day average to satisfy heat loss budgets (e.g. Bickle, 1978), whereas others argue for more sluggish tectonics due to convection being regulated by increased volumes of depleted oceanic lithosphere (Korenaga, 2006). Figure 9c indicates that slower rates of subduction (for a given slab length) lead to a reduction in buoyancy force, as cool isotherms are advected a shorter distance into the mantle. However, of the considered subduction parameter ranges, velocity variations cause the smallest change in buoyancy force.

\section{Discussion and conclusions}

Our results indicate that oceanic lithosphere derived from hotter mantle has a greater negative buoyancy, and therefore subduction potential, than lithosphere derived from cooler mantle for a wide range of subduction scenarios (Fig. 9), indicating that subduction was viable on the early Earth.

Using our results to more directly assess the likelihood of subduction on the early Earth would require two additional pieces of information. First, we would need robust estimates of oceanic lithosphere parameters at this time (i.e. prevailing lithospheric thickness, length, velocity, etc.), which remain contentious (e.g. Korenaga, 2006). Second, the negative buoyancies discussed herein would need to be converted into net 'slab pull' forces, which requires estimating the magnitudes of the forces resisting slab subduction, principally drag on the slab margins and the work done in bending the plate into a subduction zone. Intuitively, hotter ambient mantle would result in smaller viscous resisting stresses on the margins of the slab, and the work done in bending the plate into the subduction zone is unlikely to have been significantly higher than at present because this value is set by the material properties of faults and the creep strength of minerals (although whether the slab is hydrated could have an important effect on its strength). Therefore, the dominant factor in controlling ancient slab pull was likely the buoyancy of oceanic lithosphere, as explored in Fig. 9. 
In the above analysis, we have compared negative buoyancy estimates for oceanic lithosphere that is in thermal steady-state when it begins to subduct, which implicitly describes 'old' lithosphere, and gives rise to the maximum possible buoyancy force for a given set of geometrical parameters. At the present day, variations in the age of lithosphere entering subduction zones, combined with the effects of subduction rate and geometry, lead to lateral variations in slab buoyancy (Cloos, 1993). Such variations would presumably have been present (but are currently unconstrained) in the early Earth. However, the broad similarity between our negative buoyancy estimates of subducting lithosphere that is initially in thermal steady-state (Fig. 9), suggests that broad similarities would also likely exist for the subduction of younger lithosphere. As such, although our results indicate that subducting slabs in the early Earth were more negatively buoyant than those at the present day for a given set of subduction parameters, the global variations of slab buoyancies (and so driving forces) are likely to form two overlapping distributions for the two time periods. Subduction processes may therefore have been uniformitarian at least as early in the Earth's history as the Archean.

For advocates of there being no subduction on the early Earth, a related question is whether subduction needed an initiation stimulus to overcome the forces resisting the onset of subduction, until enough slab is present that the negative buoyancy overcomes this resistance. Proposed mechanisms are contentious, with leading theories invoking far-field compressional effects caused by meteorite impacts (Hansen, 2007; O'Neill et al., 2017 ) or the influence of mantle plumes (Gerya et al., 2015). However, once initiated, our results suggest that subduction could have been readily maintained for a range of possible subduction scenarios, thus causing the onset of modern-style plate tectonics, as the lithosphere was primed to subduct.

\section{Acknowledgements}

T. Holland, J. Maclennan and O. Shorttle are thanked for stimulating discussions; C. Herzberg, S. Tappe and an anonymous reviewer are thanked for comments that improved this manuscript; and R. Bendick is thanked for efficient editorial handling. This work was partly supported by the Natural Environment Research Council (NERC) grant 'Looking Inside the Continents from Space'. 
Table 1: Calculated slab component compositions (wt\%) and thicknesses (km) from fractionated pseudosection modelling of mantle melting (Fig. 1). All data and calculations given in Tables S1-6. *Thickness calculations assume a density of $3300 \mathrm{~kg} \mathrm{~m}^{-3}$ for mantle components, and $3000 \mathrm{~kg} \mathrm{~m}^{-3}$ for crustal components. $\mathrm{Mg} \#=$ mol. $\mathrm{Mg} /\left(\mathrm{Mg}+\mathrm{Fe}^{2+}\right)$.

\begin{tabular}{|c|c|c|c|c|c|c|c|c|c|c|}
\hline Composition (wt\%): & $\mathrm{SiO}_{2}$ & $\mathrm{Al}_{2} \mathrm{O}_{3}$ & $\mathrm{CaO}$ & $\mathrm{MgO}$ & $\mathrm{FeO}$ & $\mathrm{Na}_{2} \mathrm{O}$ & $\mathrm{Fe}_{2} \mathrm{O}_{3}$ & $\mathrm{Cr}_{2} \mathrm{O}_{3}$ & thickness $(\mathrm{km})^{*}$ & $\mathrm{Mg} \#$ \\
\hline $\mathrm{T}_{P}=1300^{\circ} \mathrm{C}$ crust & 48.11 & 15.63 & 13.29 & 12.11 & 8.16 & 1.98 & 0.48 & 0.24 & 7.5 & 0.73 \\
\hline $\mathrm{T}_{P}=1425^{\circ} \mathrm{C}$ crust & 47.69 & 13.33 & 12.96 & 14.31 & 9.28 & 1.64 & 0.50 & 0.31 & 13.8 & 0.73 \\
\hline $\mathrm{T}_{P}=1550^{\circ} \mathrm{C}$ crust & 47.59 & 10.71 & 11.89 & 17.40 & 10.20 & 1.33 & 0.55 & 0.33 & 24.3 & 0.75 \\
\hline $\mathrm{T}_{P}=1300{ }^{\circ} \mathrm{C}$ residual mantle & 44.48 & 1.76 & 1.59 & 43.59 & 7.92 & 0.06 & 0.27 & 0.33 & 48.5 & 0.91 \\
\hline $\mathrm{T}_{P}=1425{ }^{\circ} \mathrm{C}$ residual mantle & 44.43 & 1.72 & 1.26 & 44.25 & 7.70 & 0.06 & 0.26 & 0.32 & 70.9 & 0.91 \\
\hline $\mathrm{T}_{P}=1550{ }^{\circ} \mathrm{C}$ residual mantle & 44.30 & 1.80 & 0.97 & 44.90 & 7.41 & 0.06 & 0.24 & 0.32 & 96.6 & 0.92 \\
\hline KLB-1 fertile mantle & 44.94 & 3.52 & 3.08 & 39.60 & 7.95 & 0.30 & 0.30 & 0.32 & - & 0.90 \\
\hline
\end{tabular}


(a) KLB-1 (N)CFMASCrO fractionated P-T pseudosections @ $1300{ }^{\circ} \mathrm{C} T_{\mathrm{p}}$
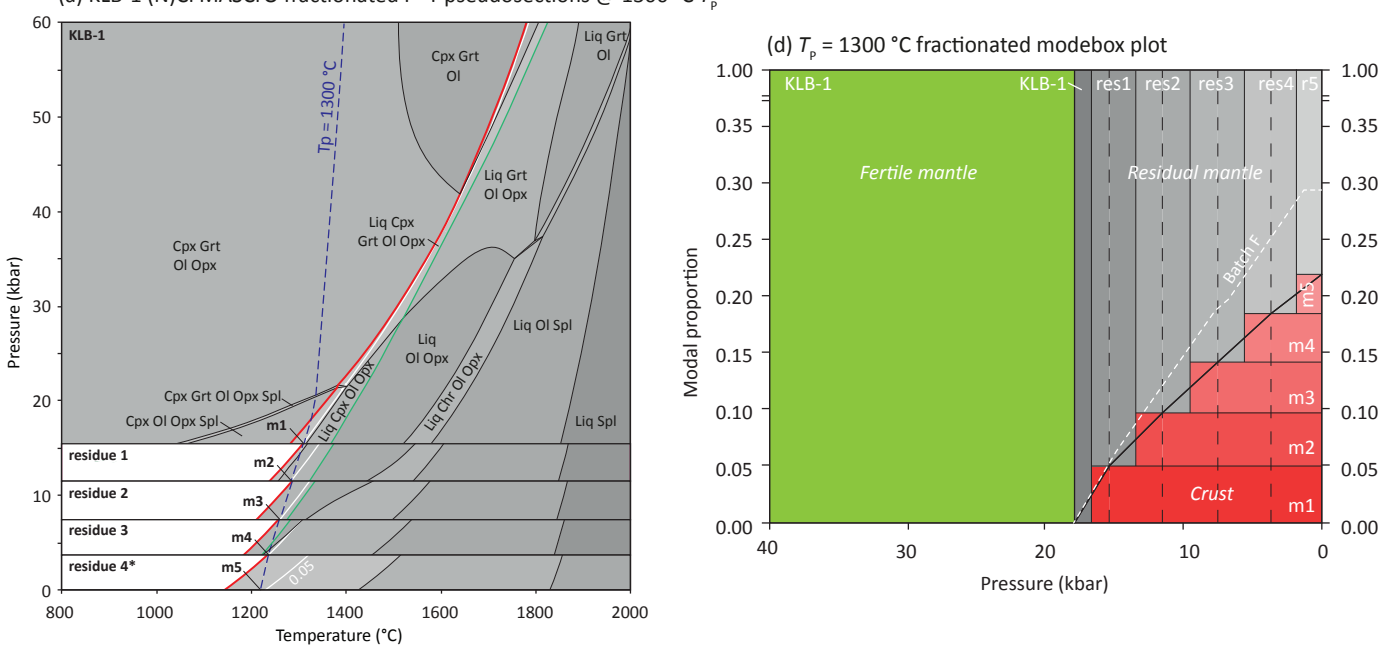

(b) KLB-1 (N)CFMASCrO fractionated P-T pseudosections @ $1425^{\circ} \mathrm{C} T_{\mathrm{p}}$

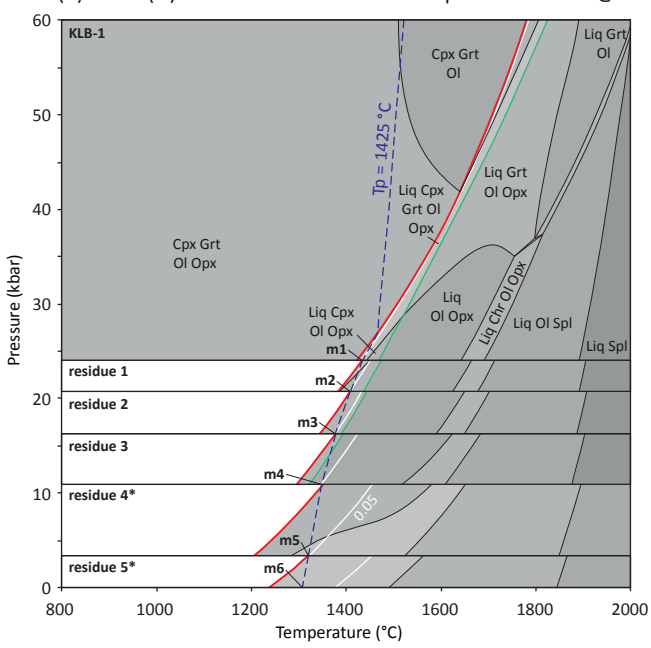

(e) $T_{\mathrm{p}}=1425^{\circ} \mathrm{C}$ fractionated modebox plot

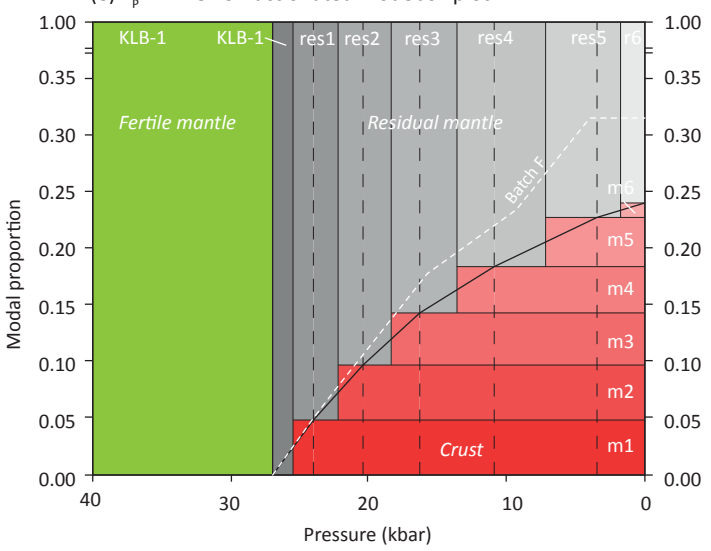

(c) KLB-1 (N)CFMASCrO fractionated P-T pseudosections @ $1550{ }^{\circ} \mathrm{C} T_{\mathrm{p}}$
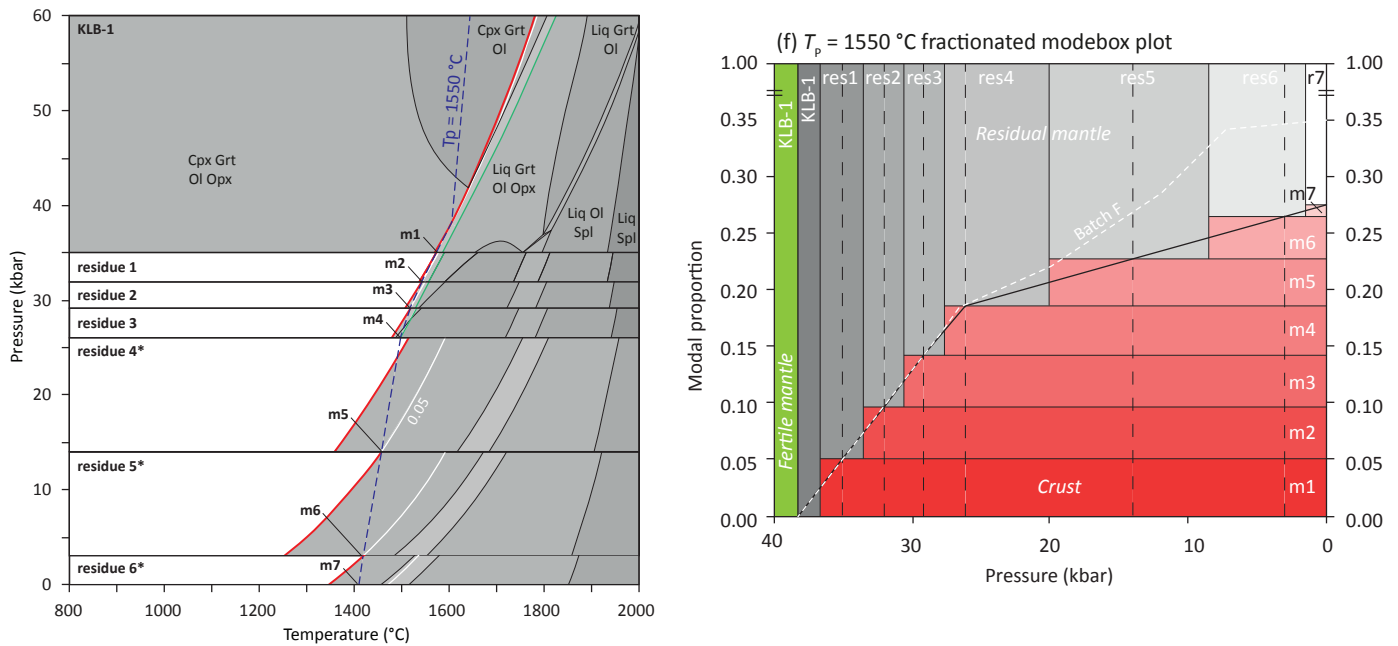

Figure 1 | Model of mantle melting with fractionation. (a-c) Pseudosections at $T_{\mathrm{P}}=(\mathrm{a})$ $1300{ }^{\circ} \mathrm{C}$, (b) $1425^{\circ} \mathrm{C}$ and (c) $1550^{\circ} \mathrm{C}$. Bold red line demarcates the solidus. Fractionation was applied when the isentrope (dark blue dashed line) intersected liquid mode $=0.05$ (white lines). ${ }^{*}$ denotes when $\mathrm{Na}_{2} \mathrm{O}$ is no longer a system component, and occurs after clinopyroxene (green lines) is exhausted. (d-f) Compositional modebox plots for $T_{\mathrm{P}}=$ (d) $1300{ }^{\circ} \mathrm{C}$, (e) $1425{ }^{\circ} \mathrm{C}$ and (f) $1550{ }^{\circ} \mathrm{C}$, Green represents fertile mantle, red shades represent crustal compositions and grey shades represent residual mantle compositions. Bulk compositions given in Tables S1-S6. Dashed black lines show fractionation points. At all pressures, the cumulative bulk composition is equal to KLB-1. Batch melt mode curves (white dotted lines; Fig. S1b-d) and fractional melt curves (bold black lines) overlain for reference. 

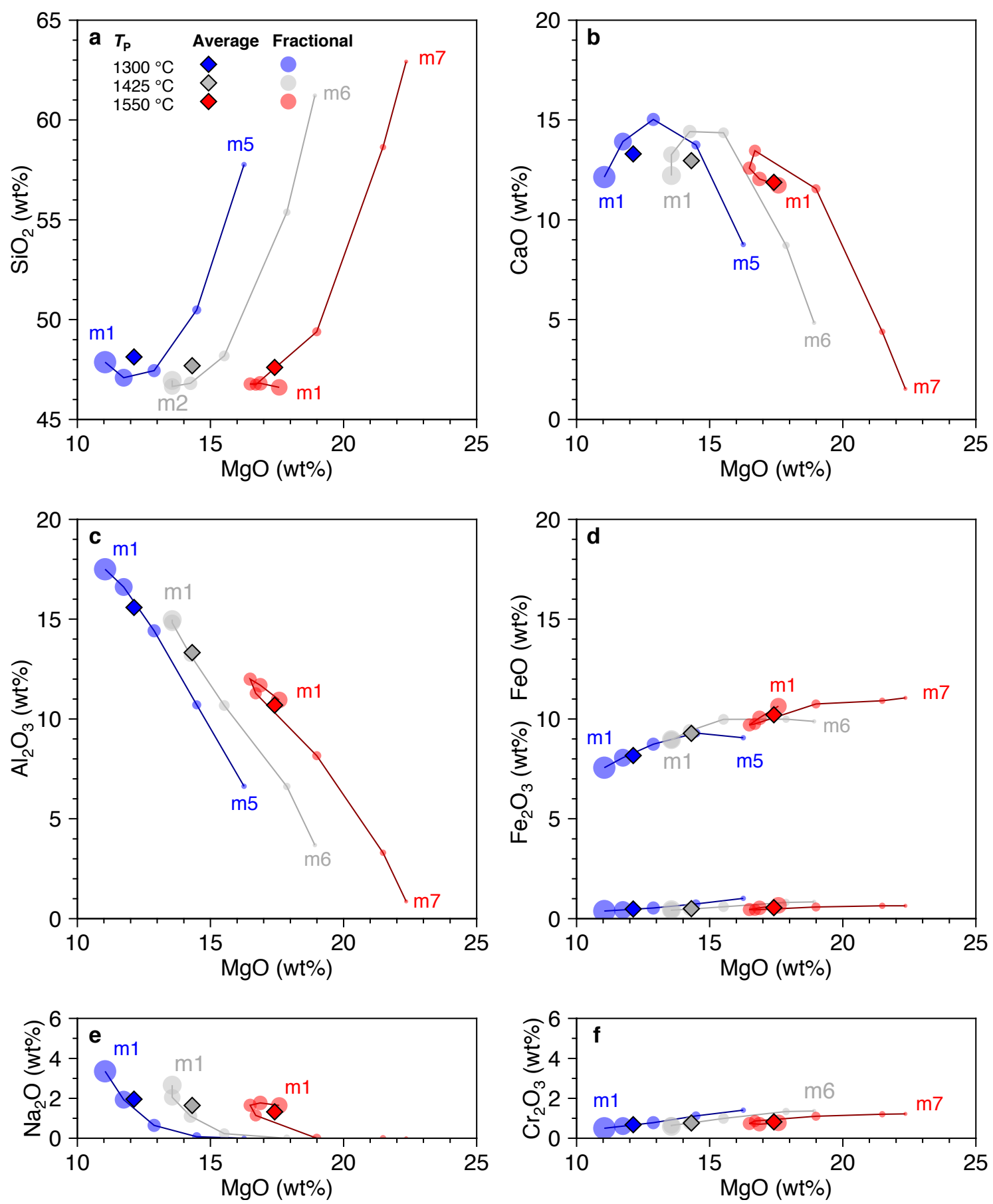

Figure 2| Evolving fractional melt compositions. Model results for $T_{\mathrm{P}}=1300{ }^{\circ} \mathrm{C}$ are blue, $1425{ }^{\circ} \mathrm{C}$ are grey, and $1550{ }^{\circ} \mathrm{C}$ are red. The diameter of the fractional melt compositions (circles) are proportional to the contribution to the depth-integrated average melt compositions (diamonds). The labels (e.g. m1) refer to the melt batches as displayed on Fig. 1 and given in Tables S1-6, with $\mathrm{m} 1$ being the first melt produced. 

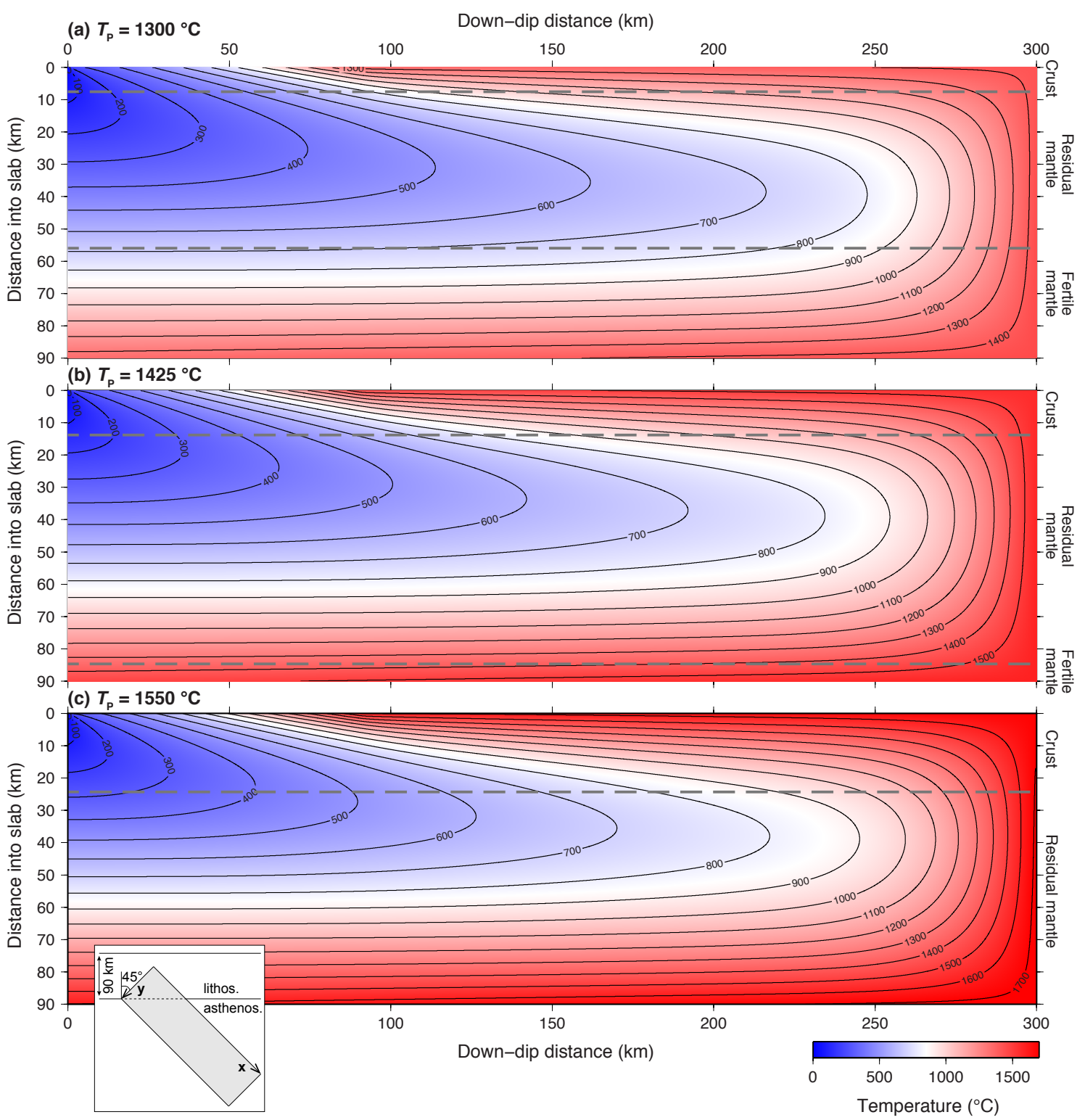

Figure 3 | Example thermal modelling results. Temperature structures are shown for $300 \mathrm{~km}$ long slabs, dipping at $45^{\circ}$, and subducting at $10 \mathrm{~mm} \mathrm{yr}^{-1}$ into mantle with (a) $T_{\mathrm{P}}=1300{ }^{\circ} \mathrm{C}$, (b) $T_{\mathrm{P}}=1425{ }^{\circ} \mathrm{C}$, and (c) $T_{\mathrm{P}}=1550{ }^{\circ} \mathrm{C}$. The y-axis 'distance into slab' is measured perpendicular to the slab upper boundary, as the coordinate system is aligned with the subducting slab (see inset). The upper surface is set to have the plate temperatures where it is less than $90 \mathrm{~km}$ deep, and then the isentropic temperature below this. The bottom and down-dip end are everywhere at the isentropic temperature to simulate the onset of subduction. The dashed grey lines show the boundaries between the compositional layers, labelled on the right. 

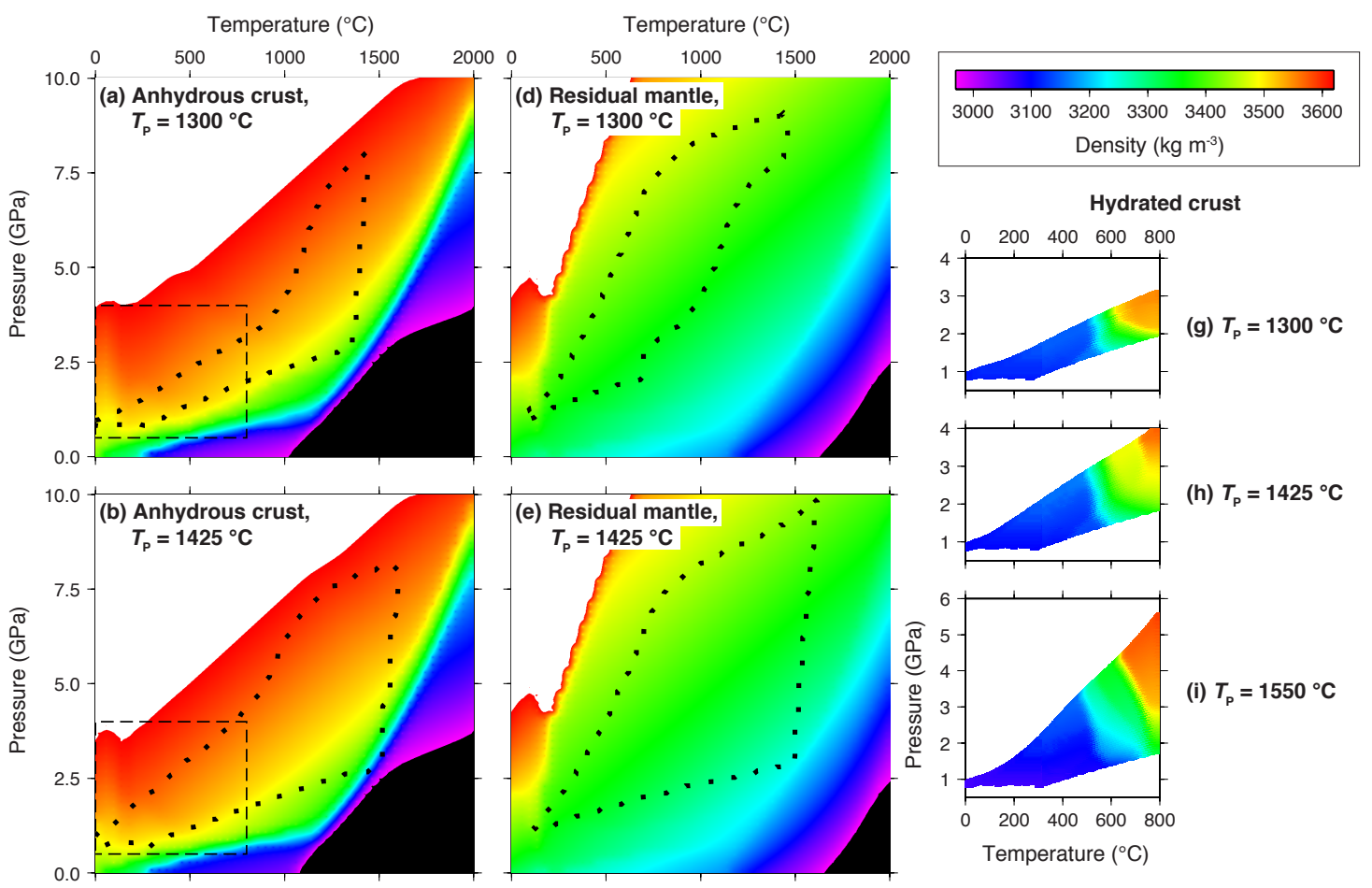
Dens

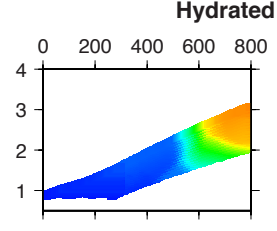

(g) $T_{\mathrm{P}}=1300^{\circ} \mathrm{C}$

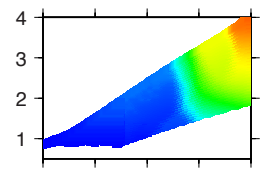

(h) $T_{\mathrm{P}}=1425^{\circ} \mathrm{C}$
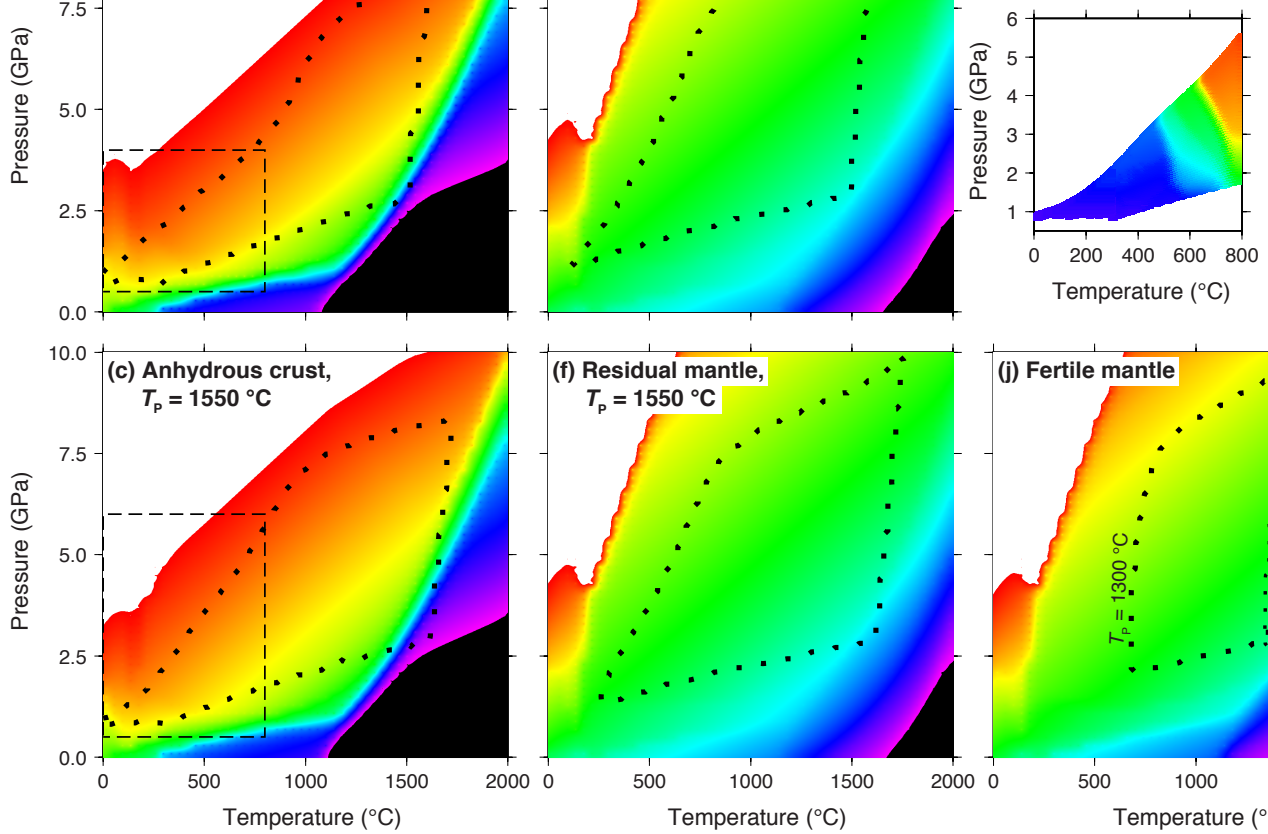

(i) $T_{\mathrm{P}}=1550^{\circ} \mathrm{C}$

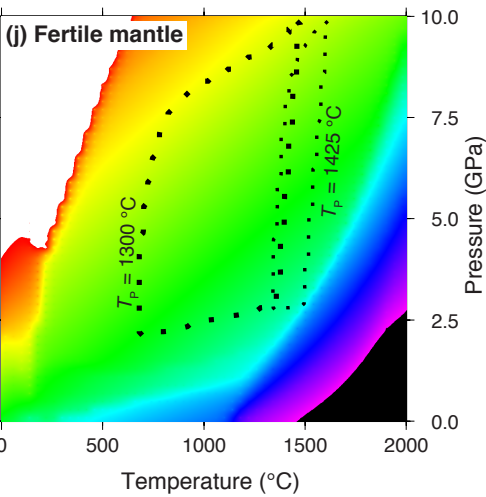

Figure $4 \mid$ Density $(\rho)$ modelling results. $P-T-\rho$ plots for $(\mathrm{a}-\mathrm{c})$ ahydrous crust and $(\mathrm{d}-\mathrm{f})$ residual mantle at variable $T_{\mathrm{P}}$. (g-i) $P-T-\rho$ plots for hydrated crust over a restricted $P-T$ range (dashed boxes, $\mathrm{a}-\mathrm{c}$ ). (j) $P-T-\rho$ plot for fertile mantle (KLB-1). Dotted polygons demarcate the $P-T$ ranges sampled by each slab component for the subduction scenarios shown in Fig. 3; see text for details. Bulk compositions given in Tables S7 \& S8. 


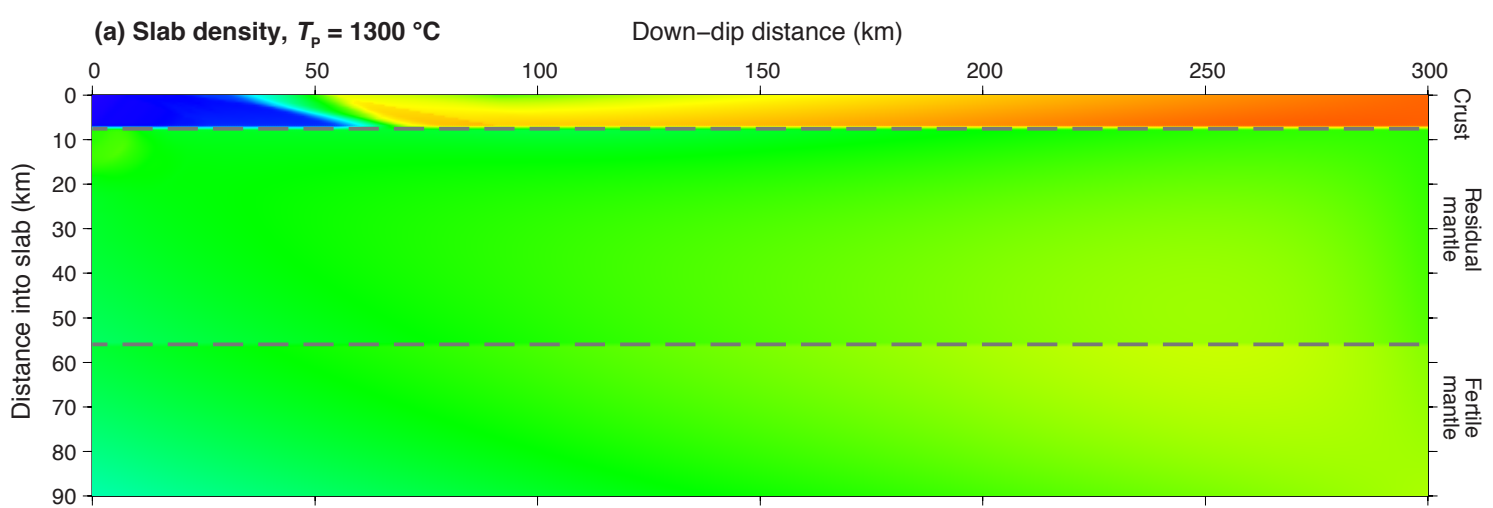

(b) Ambient mantle density, $T_{\mathrm{P}}=1300^{\circ} \mathrm{C}$

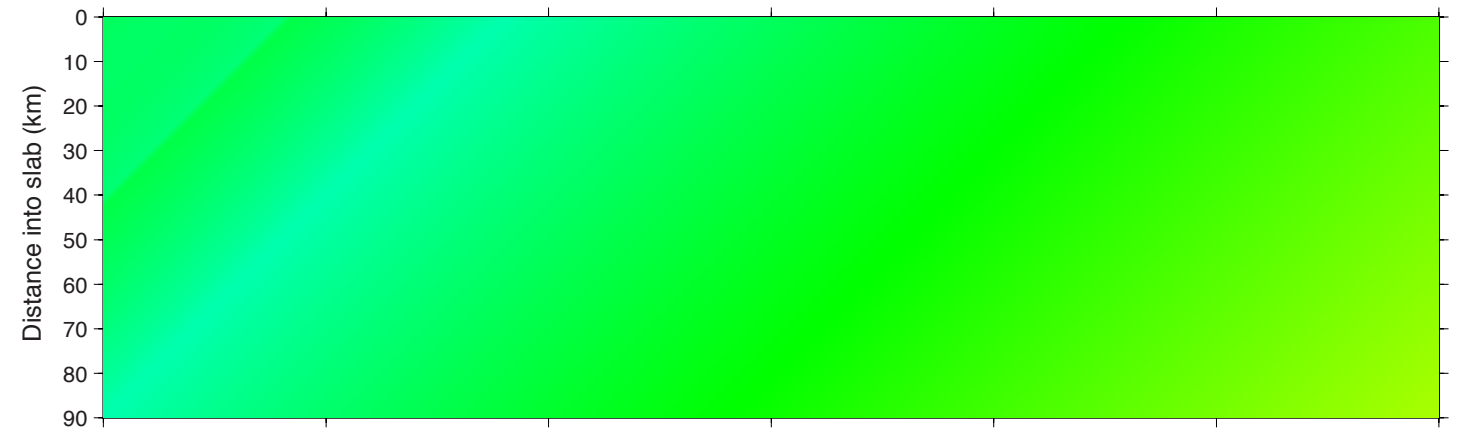

(c) Density contrast, $T_{\mathrm{P}}=1300^{\circ} \mathrm{C}$

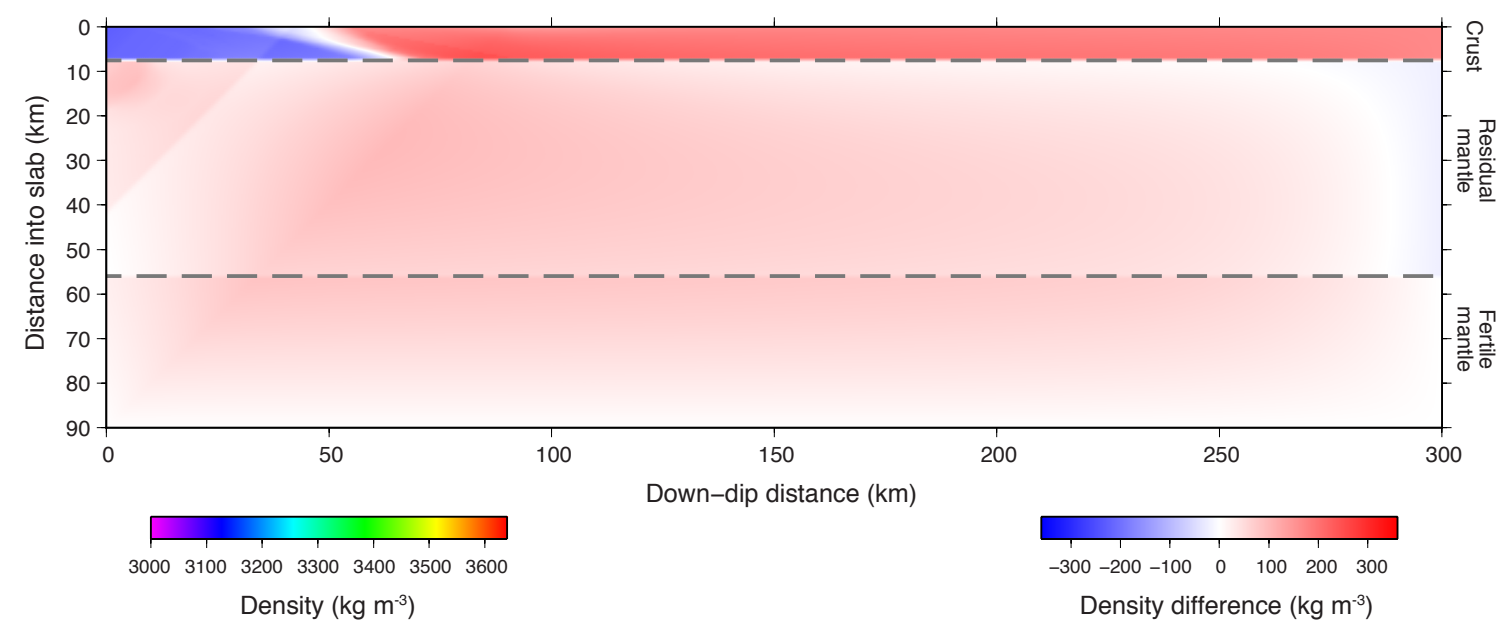

Figure $5 \mid$ Slab buoyancy calculation for $T_{\mathrm{P}}=1300{ }^{\circ} \mathrm{C}$ scenario (with a subduction velocity of $10 \mathrm{~mm} \mathrm{yr}^{-1}$ ). (a) Density structure of the slab, determined from populating Fig. 3a with relevant densities from Fig. 4 (dotted polygons). (b) Ambient mantle density. (c) Density difference (a)-(b). Integrating over the slab area and multiplying by the acceleration due to gravity gives the slab buoyancy force (negative buoyancy) $=13.6 \times 10^{12} \mathrm{~N}$ per unit length into the page (proportions: $2.6 \mathrm{TN}$ crust, $7.2 \mathrm{TN}$ residual mantle, $3.8 \mathrm{TN}$ fertile mantle). 


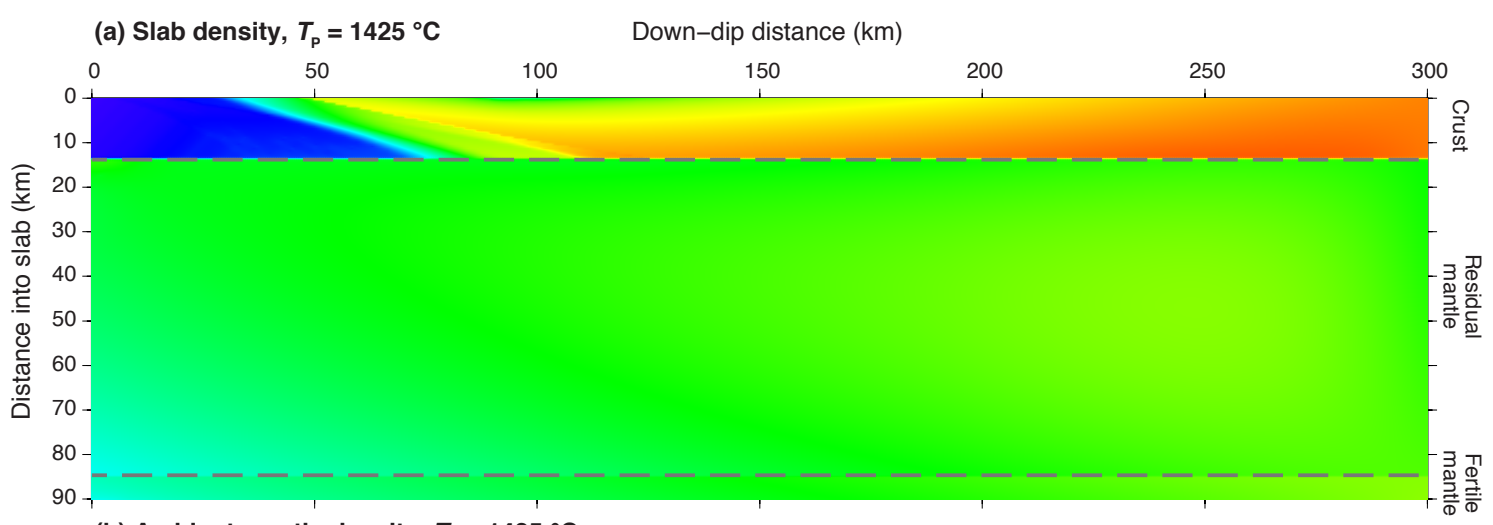

(b) Ambient mantle density, $T_{\mathrm{P}}=1425^{\circ} \mathrm{C}$

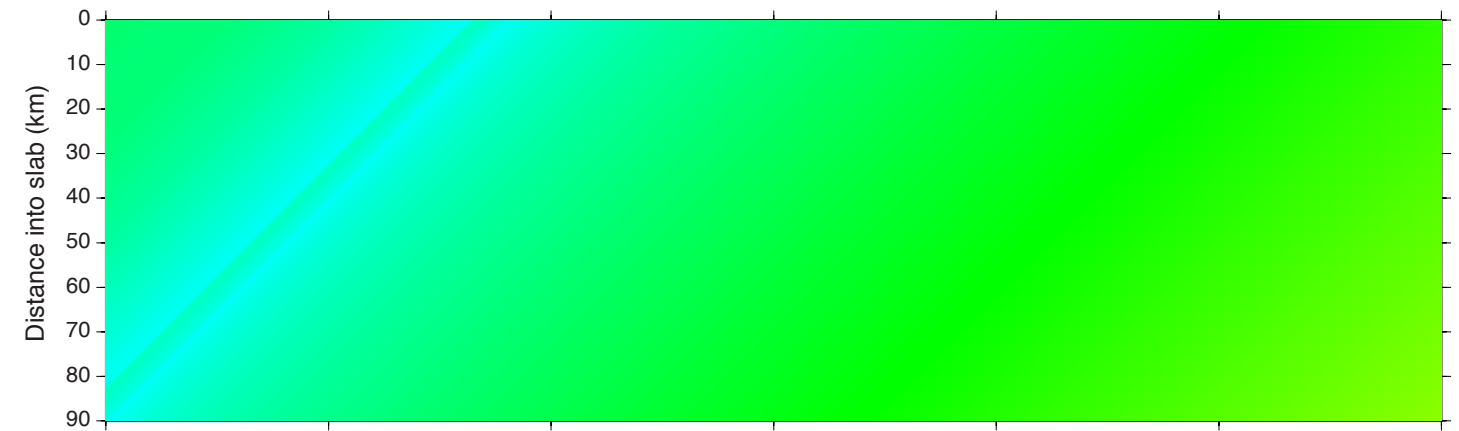

(c) Density contrast, $T_{\mathrm{P}}=1425^{\circ} \mathrm{C}$

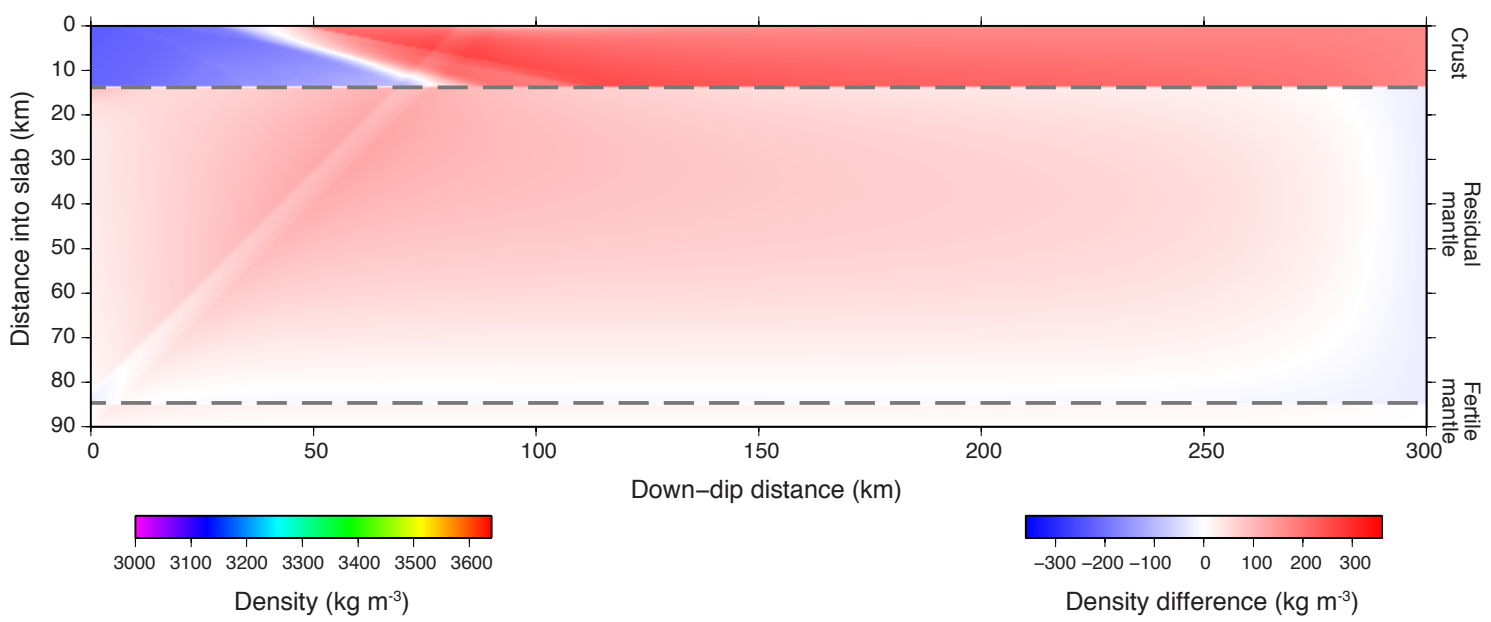

Figure 6 Slab buoyancy calculation for $T_{\mathrm{P}}=1425^{\circ} \mathrm{C}$ scenario (with a subduction velocity of $10 \mathrm{~mm} \mathrm{yr}^{-1}$ ). (a) Density structure of the slab, determined from populating Fig. 3b with relevant densities from Fig. 4 (dotted polygons). (b) Ambient mantle density. (c) Density difference (a)-(b). Integrating over the area and multiplying by the acceleration due to gravity yields the slab buoyancy force (negative buoyancy) $=14.9 \times 10^{12} \mathrm{~N}$ per unit length into the page (proportions: $5.1 \mathrm{TN}$ crust, 9.7 TN residual mantle, $0.1 \mathrm{TN}$ fertile mantle). 


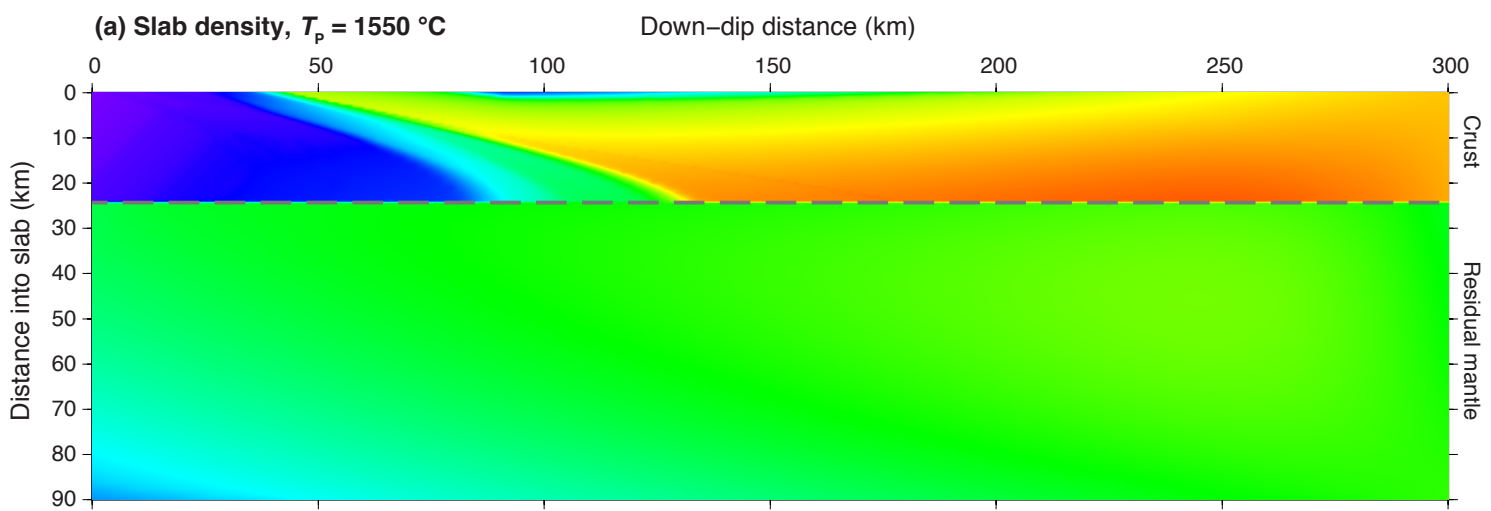

(b) Ambient mantle density, $T_{\mathrm{P}}=1550{ }^{\circ} \mathrm{C}$

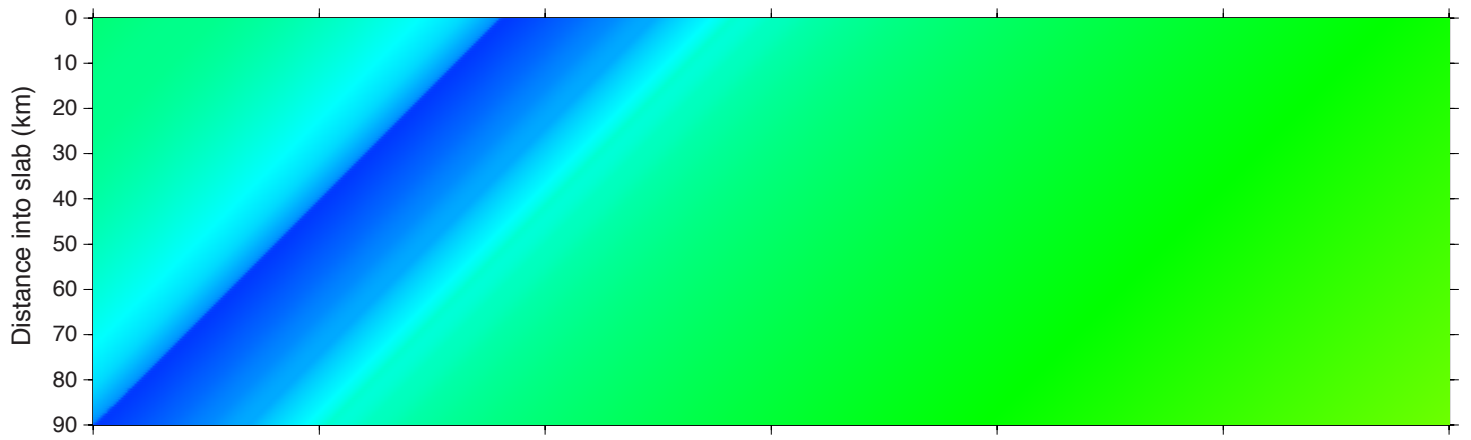

(c) Density contrast, $T_{\mathrm{P}}=1550^{\circ} \mathrm{C}$

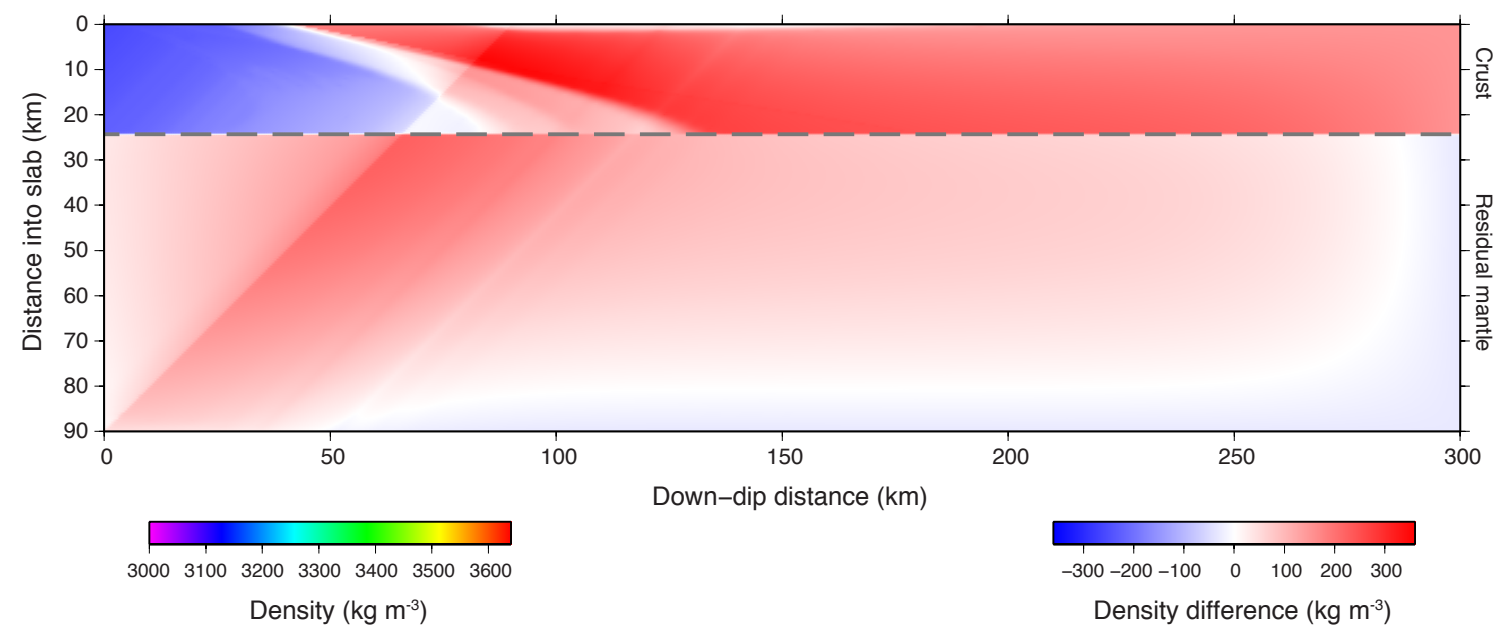

Figure $7 \mid$ Slab buoyancy calculation for $T_{\mathrm{P}}=1550{ }^{\circ} \mathrm{C}$ scenario (with a subduction velocity of $10 \mathrm{~mm} \mathrm{yr}^{-1}$ ). (a) Density structure of the slab, determined from populating Fig. 3b with relevant densities from Fig. 4 (dotted polygons). (b) Ambient mantle density. (c) Density difference (a)-(b). Integrating over the area and multiplying by the acceleration due to gravity yields the slab buoyancy force (negative buoyancy) $=19.5 \times 10^{12} \mathrm{~N}$ per unit length into the page (proportions: $8.2 \mathrm{TN}$ crust, $11.3 \mathrm{TN}$ residual mantle). 
(a) Slab density, $T_{\mathrm{P}}=1550^{\circ} \mathrm{C}$, metastability Down-dip distance (km)

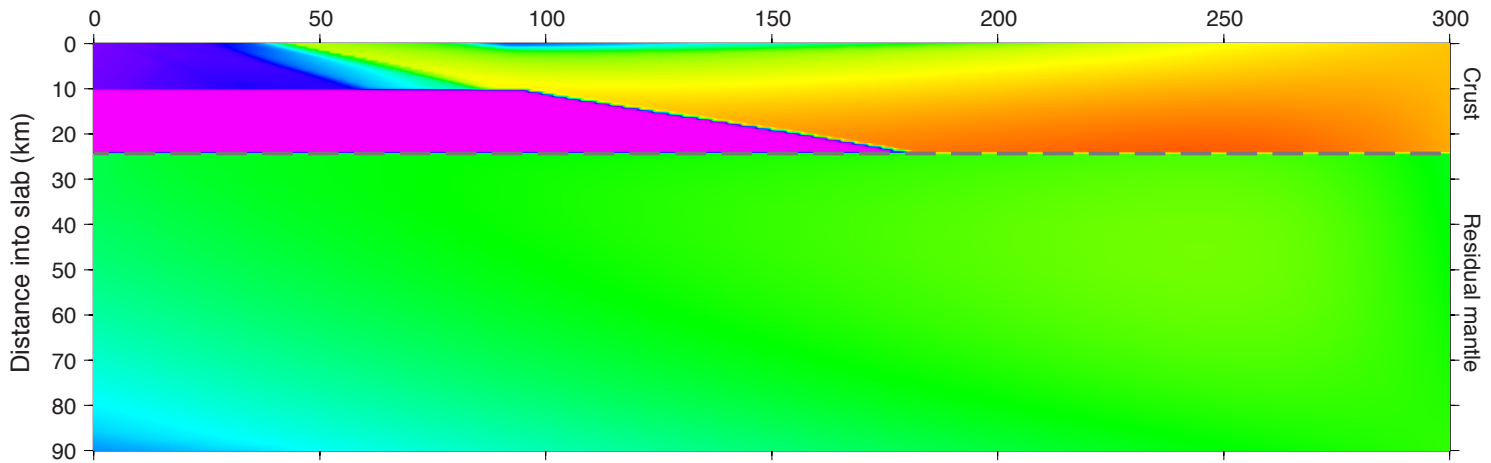

(b) Ambient mantle density, $T_{\mathrm{P}}=1550{ }^{\circ} \mathrm{C}$, metastability

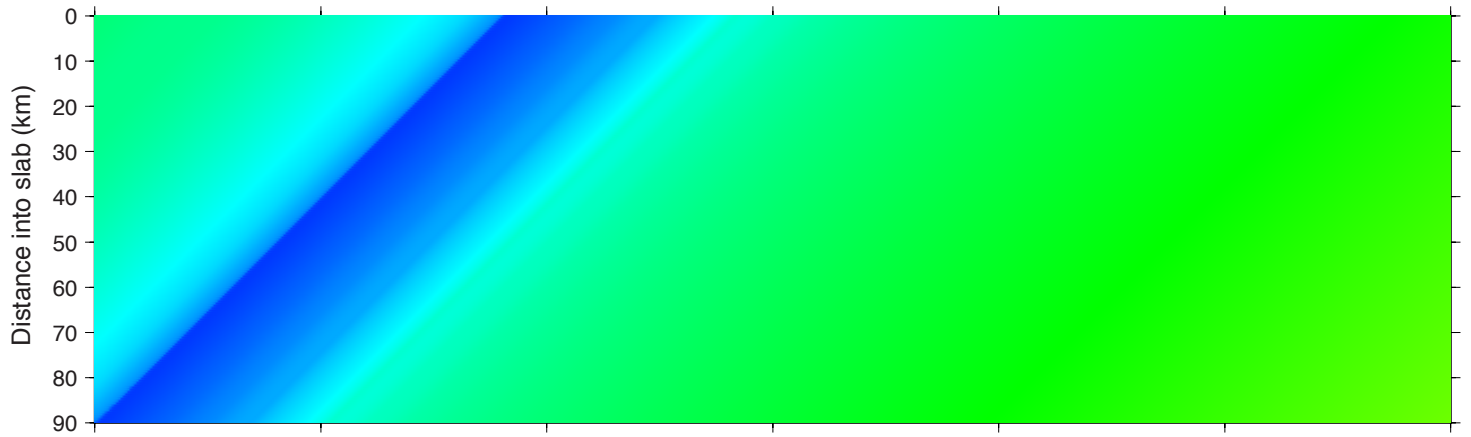

(c) Density contrast, $T_{\mathrm{P}}=1550^{\circ} \mathrm{C}$, metastability

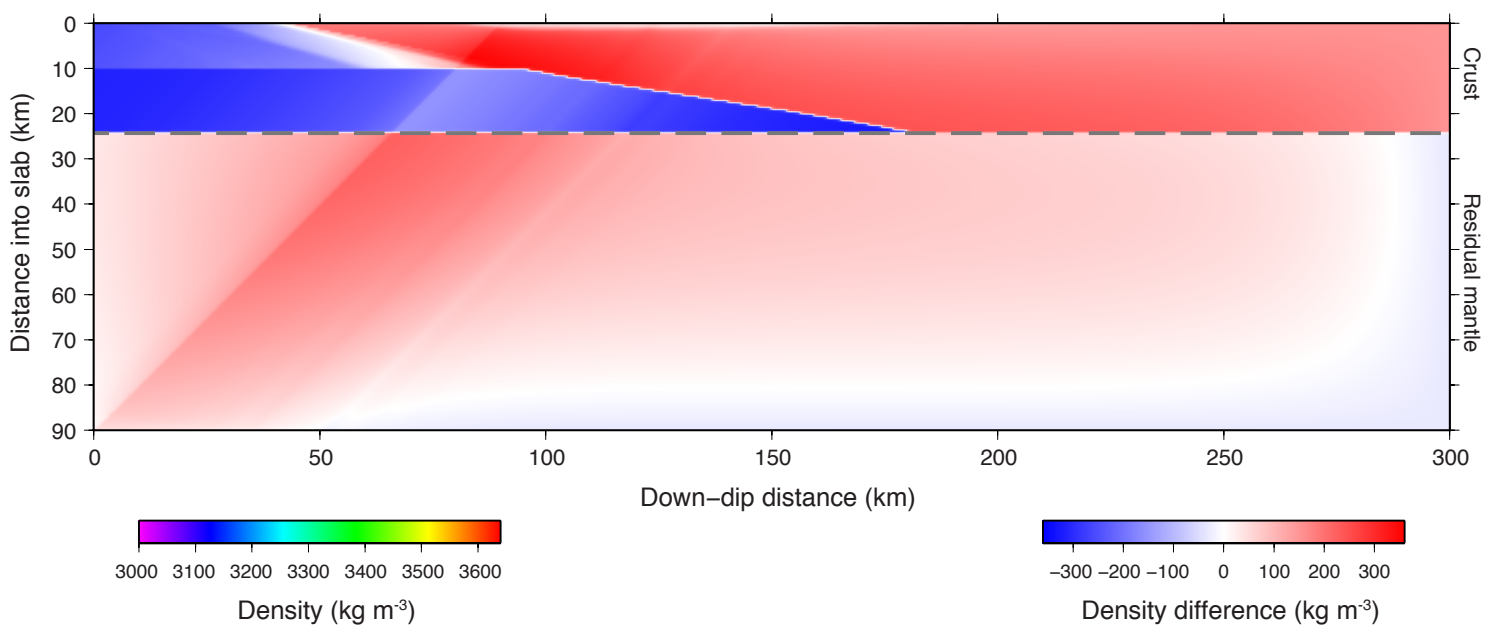

Figure 8 $\mid$ Slab buoyancy calculation for $T_{\mathrm{P}}=1550{ }^{\circ} \mathrm{C}$ scenario (with a 90-km thick slab and a metastable lower crust). (a) Density structure of the slab, with the density of the lower crust $(<10 \mathrm{~km})$ constant (i.e. metastable) at $3000 \mathrm{~kg} \mathrm{~m}^{-3}$ until $T=800{ }^{\circ} \mathrm{C}$. (b) Ambient mantle density. (c) Density difference (a)-(b). Integrating over the area and multiplying by the acceleration due to gravity yields the slab buoyancy force (negative buoyancy) $=14.7 \times 10^{12} \mathrm{~N}$ per unit length into the page (proportions: $3.5 \mathrm{TN}$ crust, 11.2 TN residual mantle). 
(a) length $=300 \mathrm{~km}$, velocity $10 \mathrm{~mm} \mathrm{yr}^{-1}$

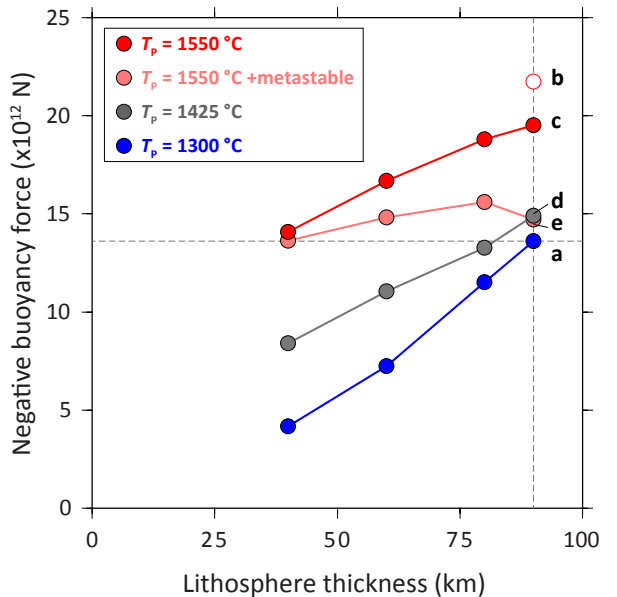

(b) thickness $=90 \mathrm{~km}$, velocity $10 \mathrm{~mm} \mathrm{yr}^{-1}$

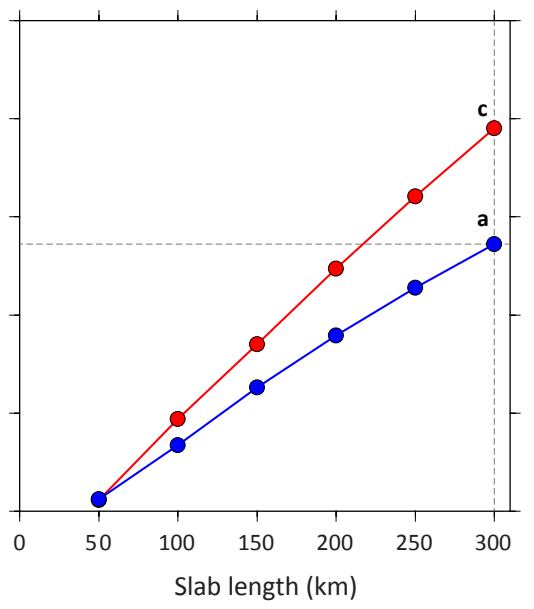

(c) length $=300 \mathrm{~km}$, thickness $=90 \mathrm{~km}$

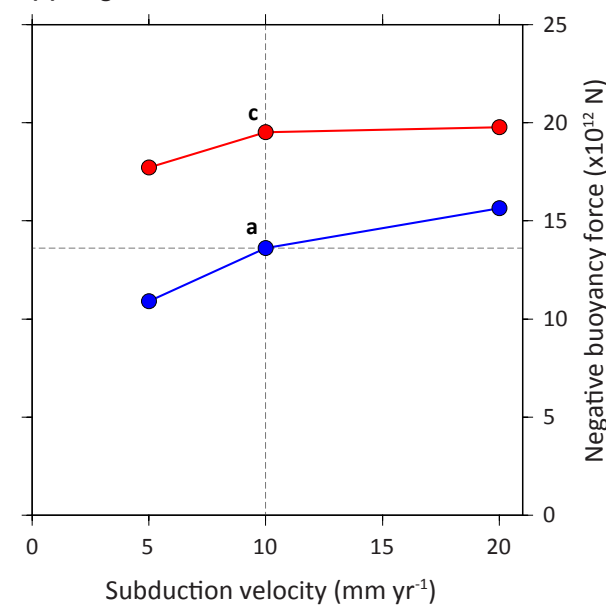

Figure 9 | Slab negative buoyancy force as a function of $T_{\mathrm{P}}$ and (a) lithosphere thickness, (b) slab length and (c) subduction velocity. Each point on Fig. 9 represents a unique thermal model, which has been been populated by data from Fig. 4 to determine the buoyancy force. Buoyancy force is per unit length into the page. Blue circles are for $T_{\mathrm{P}}=$ $1300{ }^{\circ} \mathrm{C}$ scenarios, grey circles are for $T_{\mathrm{P}}=1425^{\circ} \mathrm{C}$ scenarios, and red circles are for $T_{\mathrm{P}}=$ $1550{ }^{\circ} \mathrm{C}$ scenarios. Letters a-e refer to models discussed in the text. 'a' also corresponds to the Fig. 5 scenario, which represents the present day; 'b' refers to a hypothetical situation of present-day structure in $T_{\mathrm{P}}=1550{ }^{\circ} \mathrm{C}$; 'c' corresponds to Fig. 6; 'd' corresponds to Fig. 7; and 'e' corresponds to Fig. 8. 


\section{References}

Arndt, N. T. (1983), Role of a thin, komatiite-rich oceanic crust in the Archean platetectonic process., Geology, 11(7), 372-375, doi:10.1130/0091-7613.

Aulbach, S., \& N. T. Arndt (2019), Eclogites as palaeodynamic archives: Evidence for warm (not hot) and depleted (but heterogeneous) Archaean ambient mantle, Earth and Planetary Science Letters, 505, 162-172, doi:10.1016/j.epsl.2018.10.025.

Behn, M. D., \& T. L. Grove (2015), Melting systematics in mid-ocean ridge basalts: Application of a plagioclase-spinel melting model to global variations in major element chemistry and crustal thickness, Journal of Geophysical Research: Solid Earth, 120(7), 4863-4886, doi:10.1002/2015JB011885.

Bickle, M. (1978), Heat loss from the earth: A constraint on Archaean tectonics from the relation between geothermal gradients and the rate of plate production, Earth and Planetary Science Letters, 40(3), 301-315, doi:10.1016/0012-821X(78)90155-3.

Brown, M. (2014), The contribution of metamorphic petrology to understanding lithosphere evolution and geodynamics, Geoscience Frontiers, doi:10.1016/j.gsf.2014.02.005.

Cloos, M. (1993), Lithospheric buoyancy and collisional orogenesis : Subduction of oceanic plateaus , continental margins , island arcs , spreading ridges , and seamounts, Geological Society of America Bulletin, 105, 715-737.

Crosby, A. G., D. McKenzie, \& J. G. Sclater (2006), The relationship between depth, age and gravity in the oceans, Geophysical Journal International, 166(2), 553-573, doi: 10.1111/j.1365-246X.2006.03015.x.

Darbyshire, F. A., R. S. White, \& K. F. Priestley (2000), Structure of the crust and uppermost mantle of Iceland from a combined seismic and gravity study, Earth and Planetary Science Letters, 181(3), 409-428, doi:10.1016/S0012-821X(00)00206-5.

Davies, H. (1999), Simple analytic model for subduction zone thermal structure, Geophysical Journal International, 139(3), 823-828, doi:10.1046/j.1365-246X.1999.00991.x.

Davis, F. A., J. A. Tangeman, T. J. Tenner, \& M. M. Hirschmann (2009), The composition of KLB-1 peridotite, American Mineralogist, 94(1), 176-180, doi:10.2138/am.2009.2984.

De Capitani, C., \& K. Petrakakis (2010), The computation of equilibrium assemblage diagrams with Theriak/Domino software, American Mineralogist, 95(7), 1006-1016, doi: 10.2138/am.2010.3354.

Dhuime, B., C. J. Hawkesworth, P. A. Cawood, \& C. D. Storey (2012), A Change in the Geodynamics of Continental Growth 3 Billion Years Ago, Science, 335(March), 13341337, doi:10.1126/science.1216066. 
Emmerson, B., \& D. McKenzie (2007), Thermal structure and seismicity of subducting lithosphere, Physics of the Earth and Planetary Interiors, 163(1-4), 191-208, doi: 10.1016/j.pepi.2007.05.007.

England, P., \& C. Wilkins (2004), A simple analytical approximation to the temperature structure in subduction zones, Geophysical Journal International, 159(3), 1138-1154, doi:10.1111/j.1365-246X.2004.02419.x.

Faul, U. H. (2001), Melt retention and segregation beneath mid-ocean ridges, Nature, 410(6831), 920-923, doi:10.1038/35073556.

Foley, S. F., S. Buhre, \& D. E. Jacob (2003), Evolution of the Archaean crust by delamination and shallow subduction, Nature, 421(6920), 249-252, doi:10.1038/nature01319.

Forsyth, D. W., \& S. Uyeda (1975), On the relative importance of the driving forces of plate motion, Geophysical Journal International, 43, 163-200.

Gerya, T. V., R. J. Stern, M. Baes, S. V. Sobolev, \& S. A. Whattam (2015), Plate tectonics on the Earth triggered by plume-induced subduction initiation, Nature, 527(7577), 221225, doi:10.1038/nature15752.

Green, E., R. W. White, J. F. A. Diener, R. Powell, T. J. B. Holland, \& R. M. Palin (2016), Activity-composition relations for the calculation of partial melting equilibria in metabasic rocks, Journal of Metamorphic Geology, 34, 845-869, doi: 10.1017/CBO9781107415324.004.

Guiraud, M., R. Powell, \& G. Rebay (2001), $\mathrm{H}_{2} \mathrm{O}$ in metamorphism and unexpected behaviour in the preservation of metamorphic mineral assemblages, Journal of Metamorphic Geology, 19, 445-454.

Hansen, V. L. (2007), Subduction origin on early Earth: A hypothesis, Geology, 35(12), 1059-1062, doi:10.1130/G24202A.1.

Hawkesworth, C. J., P. A. Cawood, \& B. Dhuime (2016), Tectonics and crustal evolution, GSA Today, 26(9), 4-11, doi:10.1130/GSATG272A.1.4.

Herzberg, C., P. D. Asimow, N. Arndt, Y. Niu, C. M. Lesher, J. G. Fitton, M. J. Cheadle, \& A. D. Saunders (2007), Temperatures in ambient mantle and plumes: Constraints from basalts, picrites, and komatiites, Geochemistry, Geophysics, Geosystems, 8(2), doi:10.1029/2006GC001390.

Herzberg, C., K. Condie, \& J. Korenaga (2010), Thermal history of the Earth and its petrological expression, Earth and Planetary Science Letters, 292(1-2), 79-88, doi: 10.1016/j.epsl.2010.01.022.

Holland, T. J. B., \& R. Powell (2011), An improved and extended internally consistent 
thermodynamic dataset for phases of petrological interest, involving a new equation of state for solids, Journal of Metamorphic Geology, 29(3), 333-383, doi:10.1111/j.15251314.2010.00923.x.

Hynes, A. (2014), How feasible was subduction in the Archean?, Canadian Journal of Earth Sciences, 51(3), 286-296, doi:10.1139/cjes-2013-0111.

Jennings, E. S., \& T. J. B. Holland (2015), A simple thermodynamic model for melting of peridotite in the system NCFMASOCr, Journal of Petrology, 56(5), 869-892, doi: 10.1093/petrology/egv020.

Johnson, K. T. M., H. J. B. Dick, \& N. Shimizu (1990), Melting in the oceanic upper mantle: An ion microprobe study of diopsides in abyssal peridotites, Journal of Geophysical Research, 95(B3), 2661, doi:10.1029/JB095iB03p02661.

Klein, B. Z., O. Jagoutz, \& M. D. Behn (2017), Archean crustal compositions promote full mantle convection, Earth and Planetary Science Letters, 474, 516-526, doi: 10.1016/j.epsl.2017.07.003.

Korenaga, J. (2006), Archean geodynamics and the thermal evolution of Earth, in Archean Geodynamics and Environments, vol. 164, pp. 7-32, American Geophysical Union, doi: 10.1029/164GM03.

Langmuir, C. H., J. F. Bender, A. E. Bence, G. N. Hanson, \& S. R. Taylor (1977), Petrogenesis of basalts from the FAMOUS area: Mid-Atlantic Ridge, Earth and Planetary Science Letters, 36(1), 133-156, doi:10.1016/0012-821X(77)90194-7.

Langmuir, C. H., E. M. Klein, \& T. Plank (1992), Petrological Systematics of Mid-Ocean Ridge Basalts: Constraints on Melt Generation Beneath Ocean Ridges, Geophysical Monograph 71, pp. 183-280.

Le Bas, M. J. (2000), IUGS reclassifcation of the high-Mg and picritic volcanic rocks, Journal of Petrology, 41(10), 1467-1470.

McDonough, W. F., \& S.-S. Sun (1995), The composition of the earth, Chemical Geology, 120(January 1995), 223-253.

McKenzie, D., \& M. J. Bickle (1988), The volume and composition of melt generated by extension of the lithosphere, Journal of Petrology, 29(3), 625-679, doi: $10.1093 /$ petrology/29.3.625.

McKenzie, D., \& R. L. Parker (1967), The North Pacific: an Example of Tectonics on a Sphere, Nature, 216(5122), 1276-1280, doi:10.1038/2161276a0.

McKenzie, D., J. Jackson, \& K. Priestley (2005), Thermal structure of oceanic and 
continental lithosphere, Earth and Planetary Science Letters, 233(3-4), 337-349, doi: 10.1016/j.epsl.2005.02.005.

McKenzie, D. P. (1969), Speculations on the Consequences and Causes of Plate Motions, Geophysical Journal of the Royal Astronomical Society, 18(1), 1-32, doi:10.1111/j.1365246X.1969.tb00259.x.

Niu, Y. (1997), Mantle melting and melt extraction processes beneath ocean ridges: Evidence from abyssal peridotites, Journal of Petrology, 38(8), 1047-1074, doi: $10.1093 /$ petroj/38.8.1047.

O'Neill, C., S. Marchi, S. Zhang, \& W. Bottke (2017), Impact-driven subduction on the Hadean Earth, Nature Geoscience, 10(10), 793-797, doi:10.1038/ngeo3029.

Palin, R. M., \& R. W. White (2016), Emergence of blueschists on Earth linked to secular changes in oceanic crust composition, Nature Geoscience, 9(1), 60-64, doi: $10.1038 /$ ngeo2605.

Powell, R., T. J. B. Holland, \& B. Worley (1998), Calculating phase diagrams involving solid solutions via non-linear equations, with examples using THERMOCALC, Journal of Metamorphic Geology, 16, 577-588.

Press, W., S. Teukolsky, W. Vetterling, \& B. Flannery (1992), Numerical Recipes in FORTRAN 77: The Art of Scientific Computing, Cambridge University Press, New York.

Rapp, R., N. Shimizu, \& M. Norman (2003), Growth of early continental crust by partial melting of eclogite, Nature, 425(October), 605-609, doi:10.1038/nature01901.1.

Shirey, S. B., \& S. H. Richardson (2011), Start of the Wilson Cycle at 3 Ga Shown by Diamonds from Subcontinental Mantle, Science, 333, 434-436.

Sleep, N. H., \& B. F. Windley (1982), Archean Plate Tectonics: Constraints and Inferences, The Journal of Geology, 90(4), 363-379, doi:10.1086/628691.

Smart, K. A., S. Tappe, R. A. Stern, S. J. Webb, \& L. D. Ashwal (2016), Early Archaean tectonics and mantle redox recorded in Witwatersrand diamonds Katie, Nature Geoscience, 9(January), 255-259, doi:10.1038/NGEO2628.

Solomatov, V. S. (1995), Scaling of temperature- and stress-dependent viscosity convection, Physics of Fluids, 7(2), 266-274, doi:10.1063/1.868624.

Stern, R. J. (2005), Evidence from ophiolites, blueschists, and ultrahigh-pressure metamorphic terranes that the modern episode of subduction tectonics began in Neoproterozoic time, Geology, 33(7), 557-560, doi:10.1130/G21365.1. 
Syracuse, E. M., P. E. V. Keken, G. A. Abers, D. Suetsugu, G. Editor, C. Bina, G. Editor, T. Inoue, G. Editor, D. Wiens, G. Editor, \& M. J. Editor (2010), The global range of subduction zone thermal models, Physics of the Earth and Planetary Interiors, 183, 73-90, doi:10.1016/j.pepi.2010.02.004.

Tappe, S., K. Smart, T. Torsvik, M. Massuyeau, \& M. D. Wit (2018), Geodynamics of kimberlites on a cooling Earth: Clues to plate tectonic evolution and deep volatile cycles, Earth and Planetary Science Letters, 484, 1-14, doi:10.1016/j.epsl.2017.12.013.

Toksöz, M. N., J. W. Minear, \& B. R. Julian (1971), Temperature field and geophysical effects of a downgoing slab, Journal of Geophysical Research, 76(5), 1113-1138, doi: 10.1029/JB076i005p01113.

Turner, S., T. Rushmer, M. Reagan, \& J.-F. Moyen (2014), Heading down early on? Start of subduction on Earth, Geology, 42, 139-142.

van Hunen, J., \& J.-F. Moyen (2012), Archean Subduction: Fact or Fiction?, Annual Review of Earth and Planetary Sciences, 40(1), 195-219, doi:10.1146/annurev-earth042711-105255.

Vlaar, N. J., P. E. van Keken, \& A. P. van den Berg (1994), Cooling of the earth in the Archaean: Consequences of pressure-release melting in a hotter mantle, Earth and Planetary Science Letters, 121(1-2), 1-18, doi:10.1016/0012-821X(94)90028-0.

Weller, O. M., \& M. R. St-Onge (2017), Record of modern-style plate tectonics in the Palaeoproterozoic Trans-Hudson orogen, Nature Geoscience, 10(March), 305-311, doi: 10.1038/ngeo2904.

White, R. S., D. McKenzie, \& K. O’Nions (1992), Oceanic Crustal Thickness From Seismic Measurements and Rare Earth Element Inversions, Journal of Geophysical Research, 97(B13), 19,683-19,715.

White, W. M., \& E. M. Klein (2014), Composition of the Oceanic Crust, vol. 4, 2 ed., 457-496 pp., Elsevier Ltd., doi:10.1016/B978-0-08-095975-7.00315-6.

Zhu, W., G. A. Gaetani, F. Fusseis, L. G. J. Montesi, \& F. De Carlo (2011), Microtomography of Partially Molten Rocks: Three-Dimensional Melt Distribution in Mantle Peridotite, Science, 332(6025), 88-91, doi:10.1126/science.1202221. 